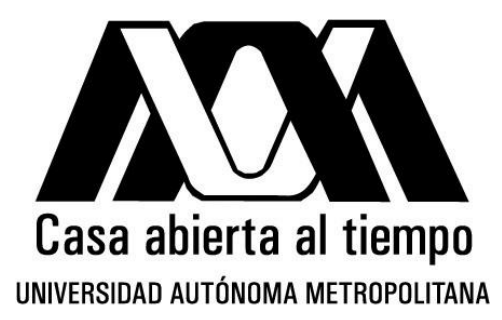

Estudio del consumo de hexadecano por un consorcio bacteriano en un biorreactor airlift

\title{
TESIS
}

Que para obtener el grado de Maestra en Biotecnología

\author{
PRESENTA
}

IBI. María Virginia Sillas Moreno

\author{
DIRECTOR
}

Dr. Mariano Gutiérrez Rojas

Febrero de 2012 
La Maestría en Biotecnología de la Universidad Autónoma Metropolitana está incluida en el Programa Nacional de Posgrados de Calidad (PNPC) del CONACYT, con la referencia 001465 
El jurado designado por la división de Ciencias Biológicas y de la salud aprobó la tesis

\section{Estudio del consumo de HXD por un consorcio bacteriano en un biorreactor} airlift

\section{Que presentó}

\section{I.B.I. María Virginia Sillas Moreno}

Comité de Tutores:

Director: Dr. Mariano Gutiérrez Rojas Universidad Autónoma Metropolitana

Asesor: Dr. Sergio Huerta Ochoa Universidad Autónoma Metropolitana

Jurado:

Presidente: Dr. Sergio Huerta Ochoa

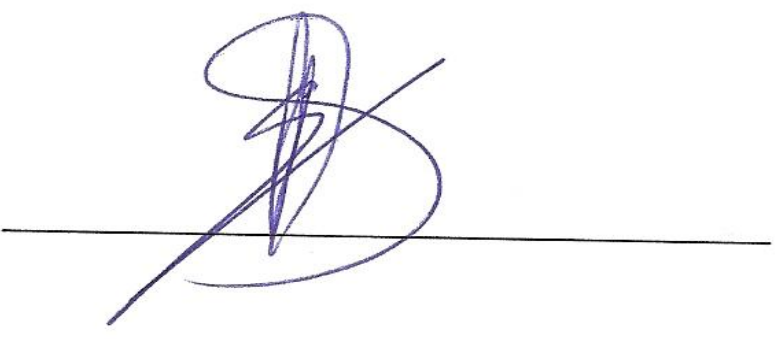

Secretario: Dra. Anne Claire Texier Valentin

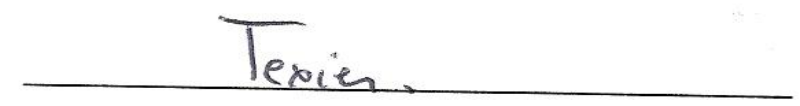

Vocal: Dr. Sergio Alejandro Medina Moreno

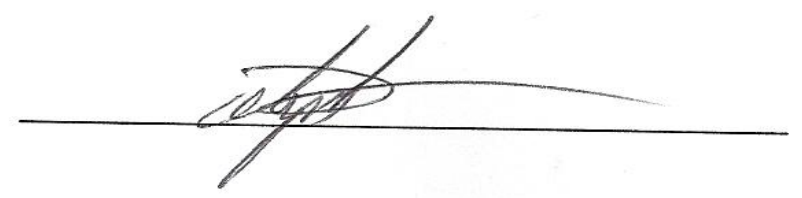

Vocal: Dr. Daniel Torres Martínez

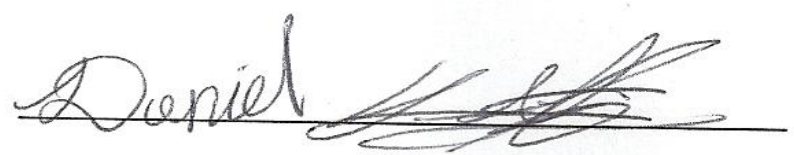


"Todo aquello que tú eres es un regalo que te ha hecho la vida. Todo aquello en lo que te conviertes, es un regalo tuyo para la vida". José Gaiarsa 


\section{Agradecimientos}

Agradezco a mis padres por su amor, confianza, por todas sus enseñanzas y buenos ejemplos que me han guiado y ayudado en la toma de decisiones a lo largo de la vida; de ellos aprendí que el valor de un ser humano no está en el exterior ni en su riqueza o poder, sino en su interior, acciones, valores y principios. Gracias a esta invaluable enseñanza he encontrado amigos maravillosos y un gran esposo.

A mis hermanas Sandra y Alejandra y a Oscar que siempre están acompañándome, por ese gran cariño que me demuestran en todo momento, por sus consejos y todas las experiencias invaluables que he pasado a su lado, me han hecho realmente feliz, los quiero.

A mis niñas Fátima y Asalette y a Byron por ser tan adorables, por ser mis compañeros de juegos, travesuras, y aventuras, también por tanto amor y recordarme que la vida es tan sencilla cuando no se olvida la gran sabiduría de ser niño.

A mi madrina Elodia que me ha mostrado el camino para la paz, la alegría, el equilibrio emocional y el crecimiento espiritual. Por confiar siempre en mi, por su apoyo y por quererme tanto.

A mi esposo Gonzalo por ser mi más grande soporte, por impulsarme a seguir siempre adelante, por su comprensión, por escucharme siempre y tener un buen consejo o una palabra de aliento, por hacerme tan feliz y compartir su vida conmigo, en fin, gracias por todo su amor el cual me ha dado más herramientas para ser una mejor persona y ser humano.

A mis amigos Christian Velázquez, Jorge Orendain, Cristian Parrapa, Jessica Peréz, Matias Manzano, Alejandro Montesinos, Leo Alvarado, Alejandro A. Cuapio, Felipe Morales, Manuel Lizardi, Olivia Tzintzun, Delia Javier, Candi Martínez, Adrián de la Torre, el tenerlos a mi lado hace inmejorable mi vida.

Al Dr. Mariano Gutiérrez Rojas por su apoyo, paciencia y por transmitirme parte de su inestimable conocimiento haciéndome así dar un gran paso más en mi formación académica.

Al Dr. Sergio Huerta por sus valiosas aportaciones a la tesis.

A mis compañeros del laboratorio W-103 y 108 por su inmenso apoyo y compañerismo, especialmente a Olivia Tzintzun y Manuel Lizardi por brindarme sus conocimientos.

Finalmente agradezco a Dios por ofrecerme todo lo maravilloso que hay en mi vida y por todas las experiencias que han sido transformadoras dándome la oportunidad de crecer como ser humano. 


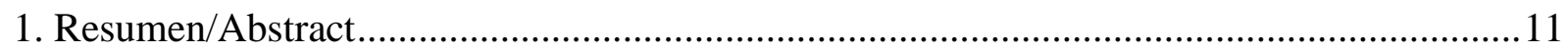

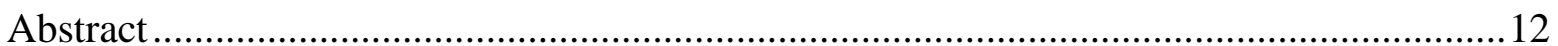

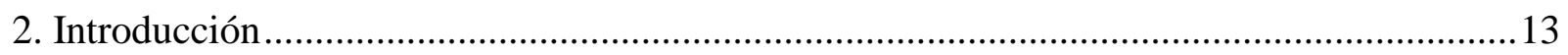

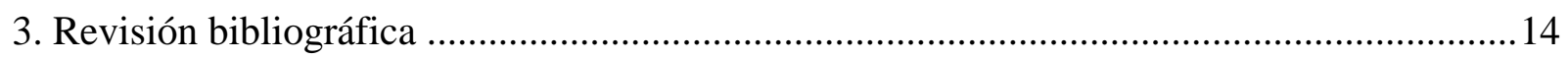

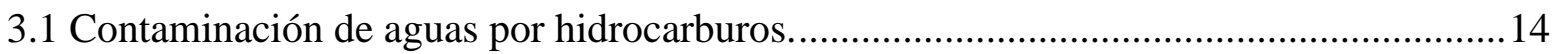

3.2 Sistemas biológicos aerobios para el tratamiento de aguas contaminadas con

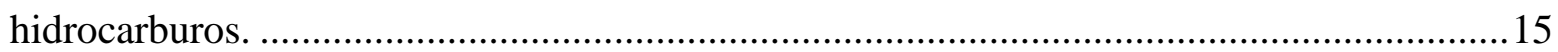

3.3. Consorcios microbianos degradadores de hidrocarburos .............................................. 17

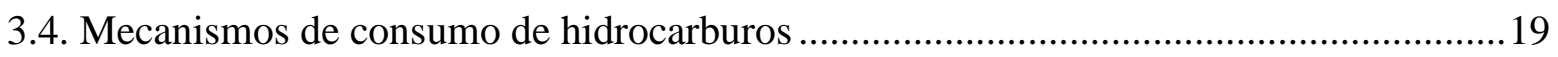

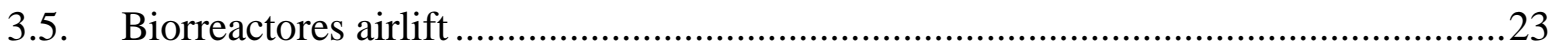

3.6. Coeficiente volumétrico de transferencia de masa $\left(\mathrm{k}_{\mathrm{L}} \mathrm{a}\right)$ y concentración de oxígeno

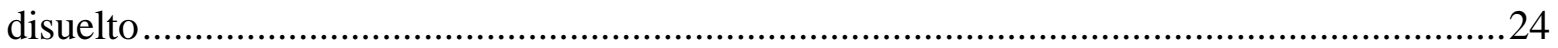

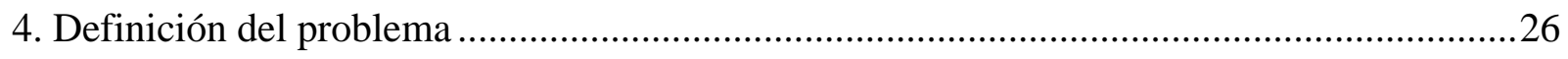

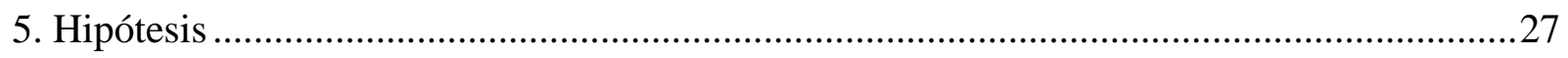

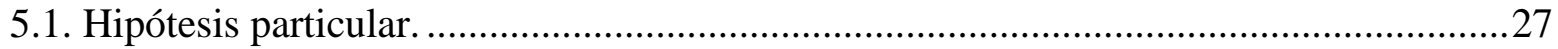

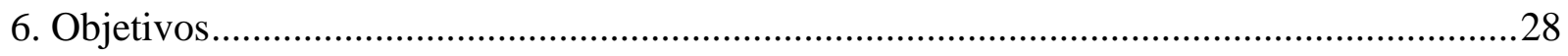

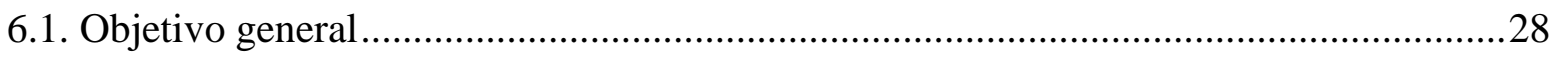

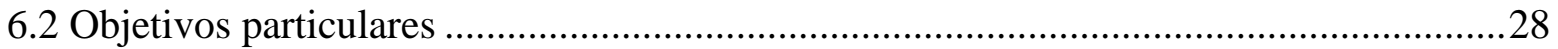

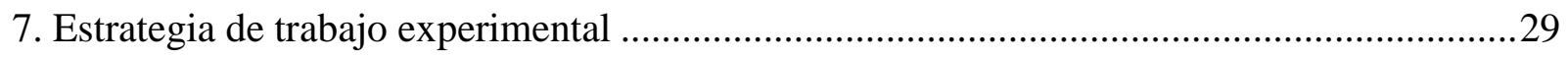

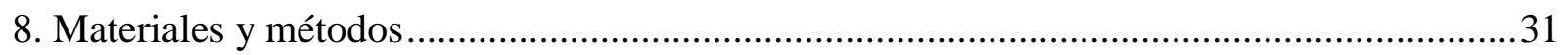

8.1. Consorcio microbiano biodegradador de hidrocarburos .................................................... 31

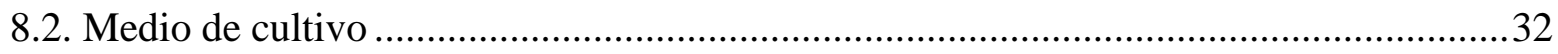

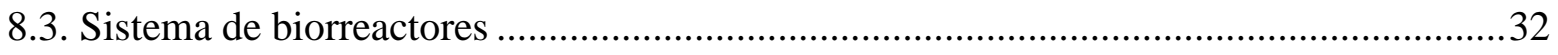

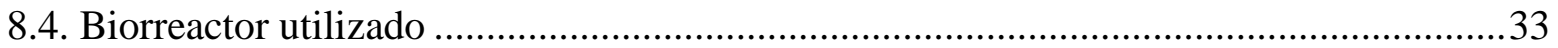

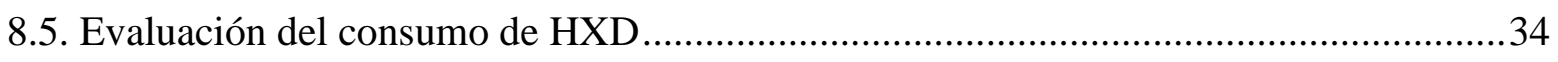

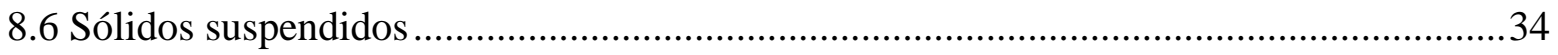

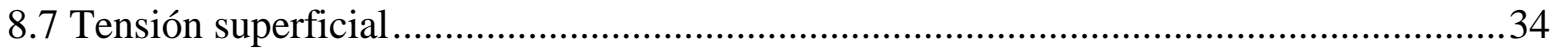

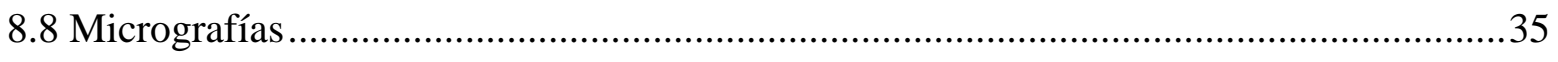

8.9 Coeficiente volumétrico de transferencia de oxígeno........................................................35

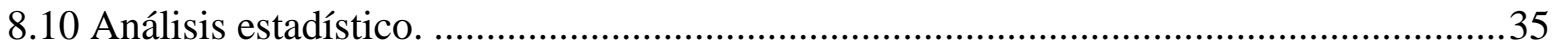

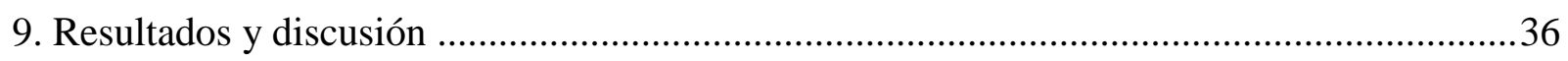

9.1. Cinéticas de consumo de HXD a velocidades de aireación constante..............................36

9.2. Cinéticas de consumo de HXD a velocidad de aireación variable ...................................40 
9.3. Efecto del aumento de células: reinoculación.......................................................44

9.4. Efecto de la presencia de biosurfactantes. .........................................................46

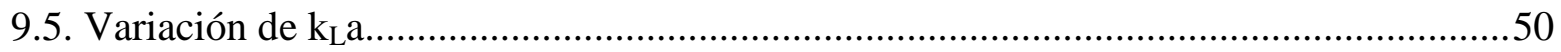

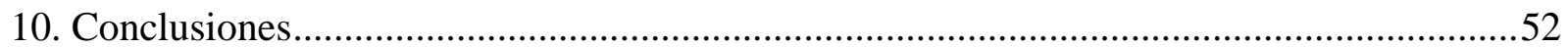

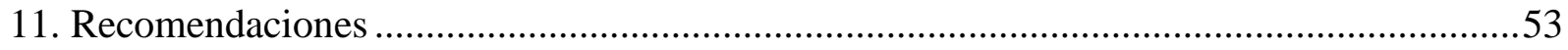

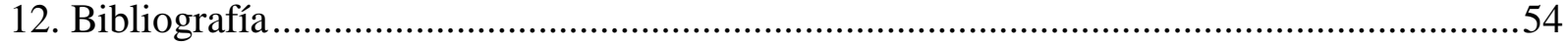


Figura 3.2.1. Ruta de degradación de alcanos......................................................................

Figura 3.4.1. Consumo bacteriano de formas solubles de HXD. ............................................18

Figura 3.4.2. Ubicación de la molécula de biosurfactante en la interfase.................................19

Figura 3.4.3. Consumo bacteriano de HXD mediado por biosurfactantes...............................20

Figura 3.4.4. Consumo bacteriano de HXD por contacto directo ............................................21

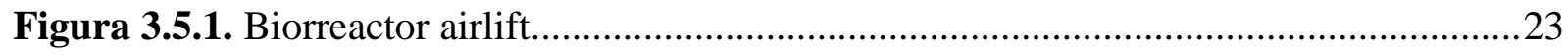

Figura 7.1.1. Síntesis de la estrategia experimental ...........................................................29

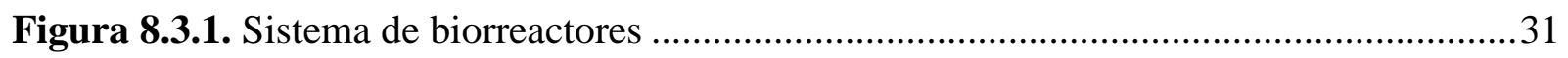

Figura 9.1.1 Cinéticas de consumo de HXD a diferentes velocidades de aireación ..................35

Figura 9.2.1. Cinéticas de consumo de HXD con Ug constante $2.7 \mathrm{~cm} \mathrm{~s}^{-1}$ y con velocidad de aireación variable .......................................................................................................

Figura 9.2.2. Tasas de consumo de HXD para cada tiempo a Ug.constantes y variable .........41

Figura 9.3.1. Cinéticas de consumo de HXD aplicando velocidad variable de aireación y

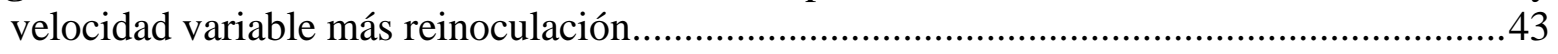

Figura 9.3.2. Comparación de las tasas de consumo a Ug variable con y sin reinoculación ...45

Figura 9.4.1. Tensión superficial ....................................................................................

Figura 9.4.2. Imágenes microscópicas ............................................................................ 48

Figura 9.5.1 Variación del $\mathrm{k}_{\mathrm{L}} \mathrm{a}$ y consumo de HXD con $\mathrm{Ug}$ de $2.7 \mathrm{~cm} \mathrm{~s}^{-1} \ldots \ldots \ldots \ldots \ldots \ldots \ldots \ldots \ldots \ldots . . . .50$ 


\section{Índice de tablas}

Tabla 9.1.1. Producción de sólidos suspendidos (SS) a las 46 h de cultivo para las cinéticas de aireación constantes... .38 


\section{Resumen/Abstract}

El refinado del petróleo es la vía principal por la cual se descargan hidrocarburos a cuerpos de agua. La presencia de los hidrocarburos en los ecosistemas tiene un impacto ambiental negativo. En el presente trabajo, se evaluaron las variables de operación que influyen en el consumo de hexadecano (HXD) por un consorcio bacteriano en un biorreactor airlift. Para evaluar el proceso se utilizaron tres diferentes velocidades de aireación constantes $(0.37,0.6$ y $2.7 \mathrm{~cm} \mathrm{~s}^{-1}$ ). Se encontró que al consumirse el $85 \%$ de la concentración inicial de HXD, el consumo se estancaba (detenia), independientemente de la velocidad de aireación utilizada. Por esta razón el resultado fue tomado como criterio para investigar otras estrategias de aireación variable que permitieran reducir o eliminar el periodo de estancamiento de consumo de HXD. También se ensayó reinocular el biorreactor antes de llegar a la etapa de estancamiento (a las $8 \mathrm{~h}$ de cultivo), sin embargo, no fue posible eliminar o disminuir el periodo de estancamiento (no consumo de HXD), y para todos los casos se encontró que el tiempo necesario para llegar a una concentración dentro de la NOM-143-SEMARNAT-2003

de $40 \mathrm{mg} \mathrm{L}^{-1}$, se encuentra en un rango de $25-46 \mathrm{~h}$, por lo que el beneficio que se tiene al aplicar la estrategia de aireación variable, es el ahorro de energía ya que se finaliza el consumo de HXD con una velocidad de aireación baja. Se evaluó también el coeficiente de transferencia de oxígeno $\left(\mathrm{k}_{\mathrm{L}} \mathrm{a}\right)$ a lo largo de la cinética para observar si durante el periodo de estancamiento de consumo de HXD pudiera haber limitación y se encontró un decremento en el $\mathrm{k}_{\mathrm{L}}$ a de $\approx 154 \mathrm{~h}^{-1} \mathrm{a} \approx 14 \mathrm{~h}^{-1}$. 


\begin{abstract}
Hydrocarbons are discharged into bodies of water, mainly, by the oil refining. The presence of hydrocarbons in ecosystems has a negative environmental impact. In this study we evaluated operation variables related to hexadecane (HXD) consumption by a bacterial consortium in an airlift bioreactor. In order to evaluate the process, we tested three constant aeration rates $(0.37$, 0.6 and $2.7 \mathrm{~cm} \mathrm{~s}-1)$. As a result, we observed that the HXD consumption was stopped when a removal of $85 \%$ was reached, regardless of the rate of aeration tested. Based on these results, we evaluated other strategies of inconstant aeration rates to reduce or eliminate the stagnation consumption phase of HXD. We also re-inoculated the bioreactor before reaching the stagnation phase (at $8 \mathrm{~h}$ of culture), however we did not observe changes. In all cases, the time required to reach a concentration within the official standard NOM-143-SEMARNAT-2003 (40 mg L-1), was observed in a range from 25 to $46 \mathrm{~h}$. The main benefit of using an aeration inconstant strategy was, energy saving, due a low aeration rate was used at the end of process. In order to relate the stagnation consumption phase of HXD with an oxygen limitation, we evaluated oxygen transfer coefficient $(\mathrm{kLa})$ during the time culture. As a result, a decrease in the kLa was observed ( $\approx 154$ h-1 to $\approx 14$ h-1).
\end{abstract}




\section{Introducción}

En el presente documento se aborda, la evaluación experimental de algunas variables de operación que influyen en la degradación de HXD en medio líquido en un biorreactor airlift operado por lotes. Con el propósito de encontrar la etapa limitante del proceso para, finalmente, reducir el tiempo del tratamiento. Las variables de operación ensayados fueron los siguientes: velocidad de aireación constante, combinación de las velocidades de aireación, el tamaño del inóculo así como el efecto de la presencia de biosurfactantes en el consumo de HXD. El objetivo del trabajo fue evaluar la viabilidad del proceso orientado al tratamiento de aguas contaminadas con hidrocarburos principalmente para el caso de las aguas residuales provenientes de las refinerías del petróleo.

Los capítulos uno y dos se refieren al resumen y la introducción al trabajo. En el capítulo tres, se presenta la revisión bibliográfica relacionada con el tema que se desarrolla, en donde se expone que en los sistemas de tratamiento de aguas contaminadas con hidrocarburos, la formación de biosurfactantes y/o bioemulsificantes son características que inciden en las tasas de consumo de los hidrocarburos y que pueden afectar negativamente, sobre todo debido a dificultades para transferir el oxígeno necesario para los microorganismos degradadores de petróleo en medios líquidos. En el capítulo cuatro se discute con detalle la definición del problema que se aborda. En el capítulo cinco, se propone la hipótesis y en el capitulo seis los objetivos de la tesis. En el capítulo siete, se plantea la estrategia global del trabajo experimental. En el capítulo ocho, se presentan los materiales utilizados y los métodos seguidos a lo largo del trabajo experimental. En el capítulo nueve se presentan los resultados obtenidos durante la etapa experimental así como la discusión de los mismos. En el capítulo diez se exponen las principales conclusiones del trabajo. 


\section{Revisión bibliográfica}

\subsection{Contaminación de aguas por hidrocarburos.}

La contaminación con hidrocarburos es un tema intensamente investigado debido a su constante ocurrencia, impacto ambiental y la importancia económica de la industria petroquímica (Saval, 2000). Xianling et al, en el 2005 mencionan que los hidrocarburos son descargados a los cuerpos de agua principalmente a través del proceso del refinado del petróleo crudo ya que las refinerías generan una gran cantidad de aguas residuales que, por la magnitud, resultan difíciles de tratar en todo el mundo.

Específicamente PEMEX-refinación informa para el 2009 una descarga total de aguas residuales de 109.35 millones de $\mathrm{m}^{3}$ día $^{-1}$ (PEMEX, 2009. Informe de Responsabilidad Social). Para contender con la contaminación que resulta de estas actividades se han implementado normas internacionales estrictas para las descargas de agua de las refinerías en muchos países (Xianling et al, 2005). Particularmente en México el límite máximo permisible de descarga de hidrocarburos esta regulado por la Norma Oficial Mexicana NOM-143SEMARNAT-2003 y es de $40 \mathrm{mg} \mathrm{L}^{-1}$ de hidrocarburos totales del petróleo.

Los hidrocarburos presentes en agua son oxidados y mineralizados mediante procesos microbianos de degradación generando un gran interés industrial y de investigación por el desarrollo de tecnologías capaces de recuperar agua contaminada (Lizardi-Jiménez, 2011). En el caso particular de las aguas residuales provenientes de las refinerías se utilizan principalmente sistemas biológicos aerobios, que resultan muy costosos, principalmente debido a la alimentación constante y excesiva de aire (Droste, 1997; Atlas y Philip, 2005; Ferrer y Seco, 2003; Gray., 2004). El suministro continuo de aire representa el mayor 
consumo de energía de este proceso y es alrededor del $70 \%$ del costo total de operación de una planta de tratamiento de aguas (Navarro et al, 2008).

Estas consideraciones económicas destacan la importancia de encontrar flujos controlados de aire que permitan entregar sólo la cantidad necesaria para que se lleve a cabo la oxidación total de los contaminantes (Lizardi-Jiménez et al, 2012).

\subsection{Sistemas biológicos aerobios para el tratamiento de aguas contaminadas con hidrocarburos.}

Los sistemas microbiológicos de eliminación de materia orgánica por la vía aerobia son los más utilizados (Ferrer y Seco, 2003), ya que tienen una gran eficiencia de biodegradación (alrededor del 80\%) (Droste, 1997; Atlas y Philip, 2005). Sin embargo estos sistemas cuentan con una gran desventaja que es la de transferir el oxígeno de forma adecuada desde la fase gas a la fase líquida (Atlas y Philip, 2005).

Para obtener adecuadas tasas de transferencia de oxígeno, los dispositivos utilizados para el mezclado en un biorreactor, invariablemente constituyen la parte central en estos procesos (Chisti, 1989). En los biorreactores el mezclado es un factor fundamental siempre que se diseña y opera de modo aerobio (Navarro et al, 2008) ya que gracias a éste se previene la sedimentación de los microorganismos, se obtiene una adecuada mezcla de agua residual, microorganismos y nutrientes (Droste, 1997) además de una adecuada transferencia de oxígeno. En biorreactores para el tratamiento de aguas contaminadas con hidrocarburos que operan con tres fases: líquida, gas y orgánica, existe otro parámetro determinante que es la transferencia de los hidrocarburos de la fase orgánica a la fase acuosa que, junto con la transferencia de oxígeno de la fase gas a la fase acuosa y la tasa de consumo de los hidrocarburos, constituyen las tres etapas críticas para la biodegradación (Quijano-Govantes, 2006).

Es así como el conocimiento del efecto de los hidrocarburos en el comportamiento de la transferencia de oxígeno permitirá evaluar su impacto en la calidad del agua y el potencial de 
las tecnologías basadas en el biotratamiento de aguas contaminadas con petróleo y combustibles aceitosos (Jajuee et al, 2006).

Una vez que los problemas generados por el transporte de masa han sido superados ocurre la biodegradación. La biodegradación aerobia de los contaminantes orgánicos tiene lugar mediante dos procesos distintos, oxidación y biosíntesis pero si el suministro de nutrientes, en forma de materia orgánica, se vuelve limitante, entonces el tejido celular microbiano será auto-oxidado (respiración endógena) por los microorganismos para obtener energía (Gray, 2004).

Especificamente la ruta aerobia de degradación de alcanos se muestra en la Figura 3.1. La ruta comienza con la oxidación del grupo terminal metilo del alcano hasta formar un alcohol, esto mediado por dos tipos de enzimas: monooxigenasas y dioxigenasas; posteriormente los alcoholes son oxidados a sus ácidos grasos correspondientes que a su vez son utilizados en la ruta catabólica de la $\beta$-oxidación (Van-Hamme et al, 2003). 

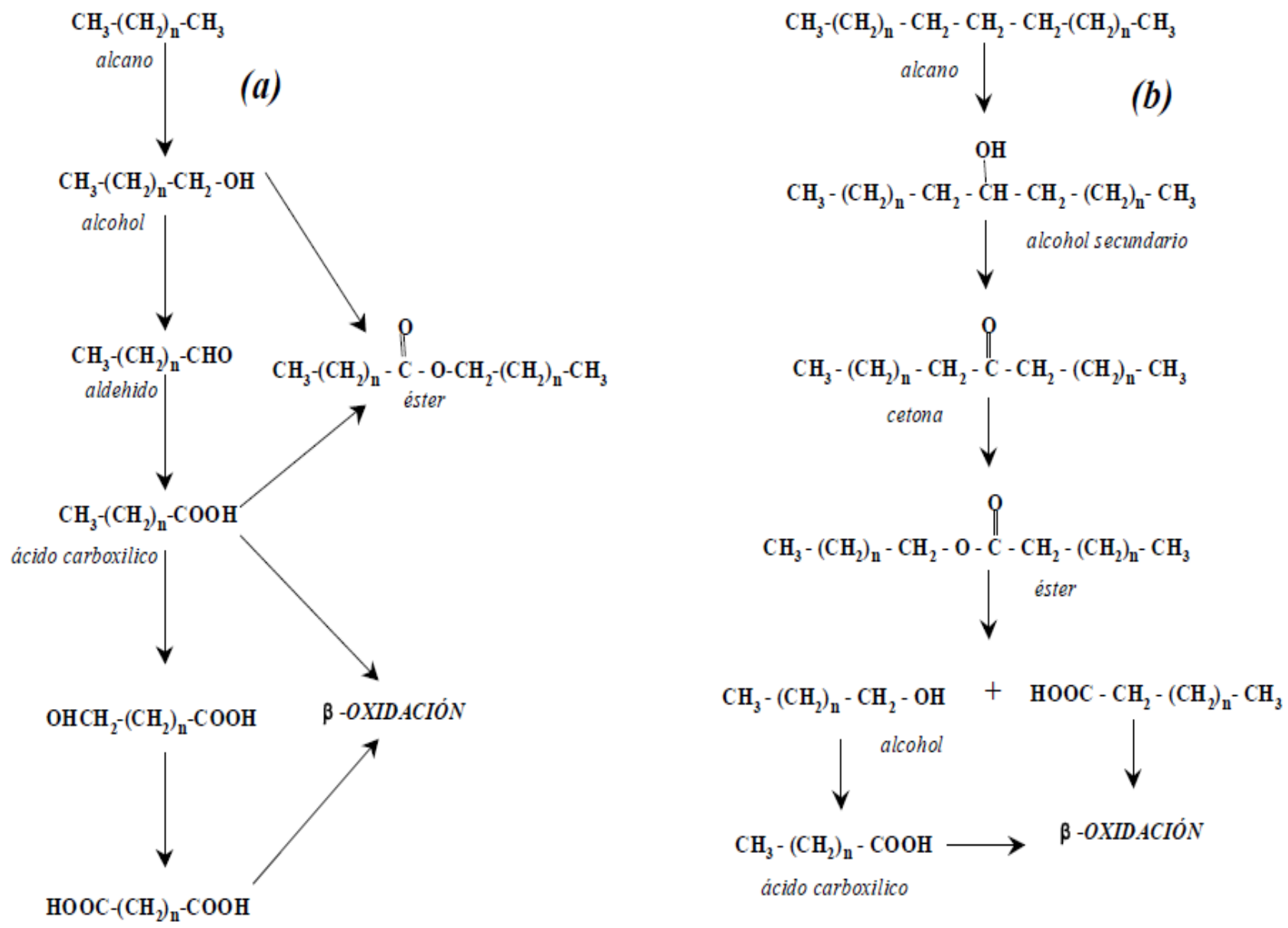

Figura 3.2.1. Ruta de degradación de alcanos.

\subsection{Consorcios microbianos degradadores de hidrocarburos}

Se ha encontrado que la mineralización (transformación hasta $\mathrm{CO}_{2}$ y agua) de mezclas complejas de hidrocarburos, por lo general requiere la coexistencia y la cooperación efectiva de varios microorganismos especializados conocidos como consorcios microbianos, con especificidad por los sustratos complementarios (Zanaroli et al, 2010). Estos consorcios se seleccionan naturalmente después de la exposición directa con los contaminantes, como en el caso del petróleo, distinguiendo a los microorganismos que componen al consorcio como aquellos con mayor capacidad degradadora dentro de una comunidad microbiana nativa 
(Röling et al, 2002). Las comunidades nativas que se seleccionan mejoran siempre la degradación de hidrocarburos en suelo, agua y sedimentos (Gargouri et al, 2011). Los consorcios microbianos degradadores de hidrocarburos han sido identificados y, algunos, aislados directamente de suelos, sedimentos, lodos así como de las raíces de algunas plantas que proliferan en los sitios contaminados con petróleo. Particularmente en el caso de las plantas, el microambiente que se desarrolla en la rizósfera de estas plantas promueve el crecimiento de poblaciones microbianas que han demostrado ser eficaces degradadoras (DíazRamírez et al, 2004). Un trabajo reciente (Tzintzun-Camacho et al, 2012), cultivando un consorcio constituido por: Xanthomonas sp, Acinetobacter bouvetii, Shewanella sp y Defluvibacter lusatiensis enfatizan que la dinámica de poblaciones y la interrelación entre las cepas constituyentes confieren a los consorcios una cierta capacidad especial para degradar hidrocarburos, como el HXD. En una de las cepas se identificó el gene que codifica para la síntesis de la enzima alcano monooxigenasa, alk-B. Esta cepa fue capaz de degradar hasta el $46 \%$ del HXD inicial y otra de las cepas del consorcio (Acinetobacter bouvetii) produjo un biosurfactante que favoreció el consumo de HXD (72 \%). El HXD es un sustrato de baja solubilidad en agua $\left(\sim 10^{-7} \mathrm{mg} \mathrm{L}^{-1}\right)$ que puede presentarse en formas libres (gotas macroscópicas y soluble) y/o en formas emulsificadas (microgotas) (Mehrnia et al, 2005), siempre y cuando se encuentre en presencia de agentes surfactantes, con lo que aumenta su concentración en la fase acuosa $\left(62 \mathrm{mg} \mathrm{L}^{-1}\right.$ ) (Quijano et al, 2010) y con esto su biodisponibilidad. Una vez biodisponible, el HXD es una fuente de carbono y energía para muchos microorganismos tanto en cultivos puros (Pepi et al, 2005) como en cultivos mixtos como los consorcios microbianos (Medina-Moreno et al, 2005). La biodegradación de hidrocarburos, como el HXD, en medios líquidos usualmente requiere la cooperación de varias especies microbianas, con diferentes capacidades metabólicas. Se ha demostrado (Ghazali et $a l, 2004)$ que el uso de consorcios microbianos produce un aumento en la tasa de consumo de los hidrocarburos con respecto a las tasas de consumo de cepas puras. En los consorcios, algunas cepas poseerían el genotipo para degradar hidrocarburos y otras la capacidad de producir biosurfactantes (Saravanan et al, 2009). En el presente trabajo, se utilizó al HXD como molécula modelo de fácil detección en el laboratorio. 


\subsection{Mecanismos de consumo de hidrocarburos}

Abbasnezhad et al, en el 2011 mencionan tres mecanismos de consumo de hidrocarburos:

1. Consumo de las formas solubles. En este tipo de consumo el sustrato sólo se puede utilizar cuando se disuelve en el medio acuoso. De acuerdo con este mecanismo, si el sustrato esta presente como una fase pura, la solubilidad de este en el agua será el factor más importante que controlará la velocidad de biodegradación. Si el sustrato es una mezcla de hidrocarburos, la velocidad de degradación dependerá de la solubilidad de la mezcla.

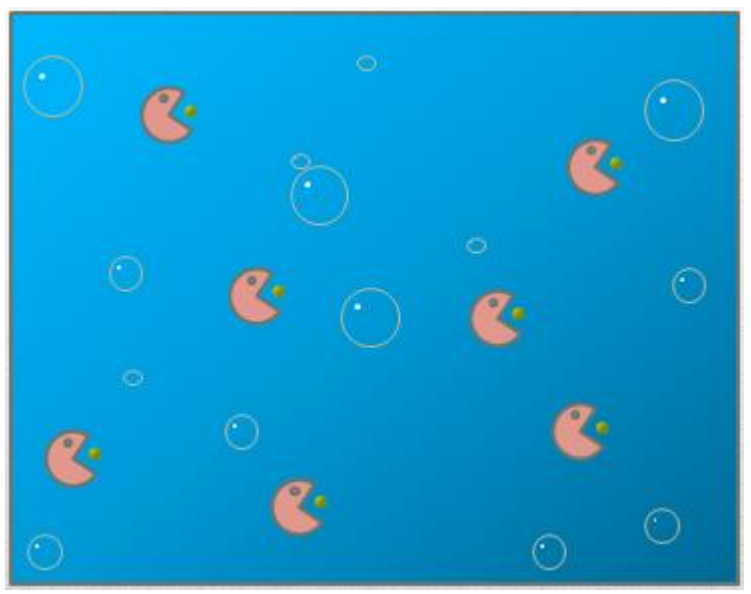

Figura 3.4.1. Consumo bacteriano de formas solubles de HXD.

2. Consumo mediado por biosurfactantes. Este mecanismo de consumo implica la excreción de compuestos (por ejemplo, biosurfactantes) por los microorganismos.

Los biosurfactantes son un grupo estructuralmente diverso capaces de disminuir la tensión superficial y son producidos por microorganismos. Todos son amfifílicos por lo que poseen 
dos partes: una polar (hidrofílica) y una no polar (hidrofóbica) (Pacwa-Płociniczak et al, 2011).

Debido a su estructura amfifílica, los biosurfactantes permiten incrementar la biodisponibilidad de los compuestos hidrofóbicos tales como los hidrocarburos facilitando su biodegradación. Los biosurfactantes se acumulan en la interfase entre dos fluidos inmiscibles, o entre un líquido y un sólido. Mediante la reducción de la tensión superficial (líquido-aire) y la tensión interfacial (líquido-líquido) que reducen la fuerza de repulsión entre dos fases diferentes, permitiendo que las fases interactúen con mayor facilidad (Pacwa-Płociniczak et al, 2011). En la Figura 3.4.2 se esquematiza la ubicación de una molécula de biosurfactante en la interfase ya sea líquido-aire o líquido-líquido.

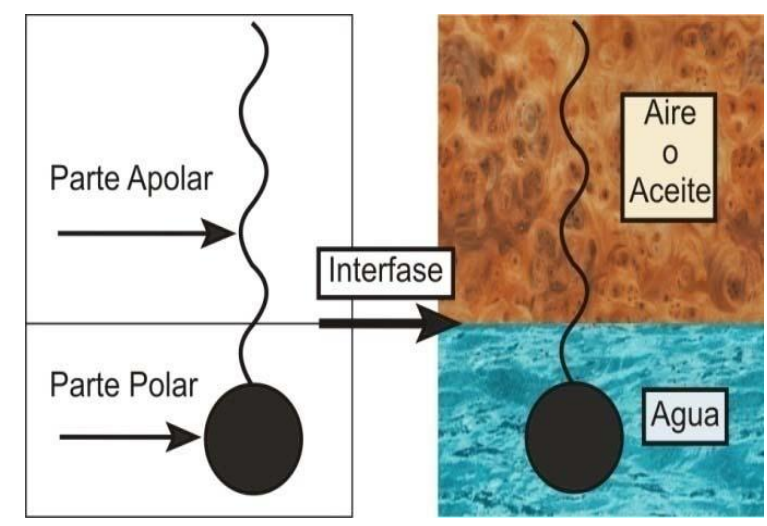

Figura 3.4.2. Ubicación de la molécula de biosurfactante en la interfase. (Riojas-González et $a l, 2010)$.

Los biosurfactantes se clasifican de acuerdo a su composición química, peso molecular, propiedades físico-químicas, modo de acción y origen bacteriano. Basado en el peso molecular se dividen en biosurfactantes de bajo peso molecular y pueden ser glicolípidos, fosfolípidos y lipopéptidos; y en biosurfactantes / bioemulsificantes de alto peso molecular y pueden contener polisacáridos, proteínas anfipáticas, lipopolisacáridos o mezclas complejas de estos biopolímeros (Martínez-Checa et al, 2007). 
El uso de biosurfactantes puede mejorar la eficacia de la biorremediación de sitios contaminados con hidrocarburos mediante dos mecanismos. El primero incluye el aumento de la biodisponibilidad del sustrato para los microorganismos mientras que el otro consiste en la interacción con la superficie celular que aumentando su hidrofobicidad permite que los sustratos hidrofóbicos se asocien más fácilmente con las células bacterianas (PacwaPłociniczak et al, 2011).

Se espera que los biosurfactantes además de disminuir la tensión interfacial contribuyan a mejorar la biodegradación de los hidrocarburos facilitando la movilización, solubilización o emulsión (Pacwa-Płociniczak et al, 2011; Asgharpour et al, 2010). Sin embargo Painmanakul et al en el 2005 encontraron que la presencia de biosurfactantes puede interferir en la degradación de hidrocarburos afectando la generación de burbujas en biorreactores de columna de burbujas y los diferentes parámetros de transferencia de masa, como el coeficiente volumétrico de transferencia de masa $\left(\mathrm{k}_{\mathrm{L}} \mathrm{a}\right)$. Así se debe considerar la utilización de un biorreactor que permita tener altas tasas de transferencia de oxígeno para los procesos de tratamiento de aguas contaminadas con hidrocarburos u otros sustratos aceitosos en los que se producen biosurfactantes un biorreactor con estas características son los biorreactores airlift.

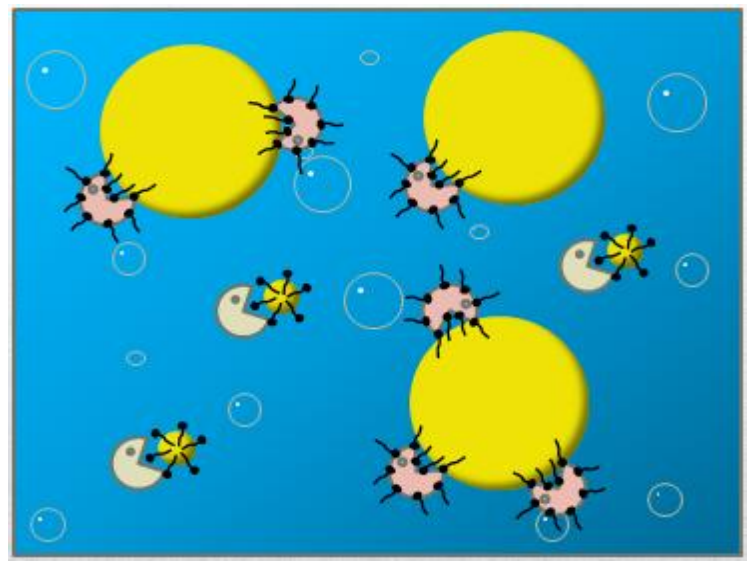

Figura 3.4.3. Consumo bacteriano de HXD mediado por biosurfactantes.

3. Consumo por contacto directo. Este mecanismo implica que las células sean capaces de adherirse a los compuestos orgánicos. 
En la mayoría de los organismos capaces de degradar hidrocarburos, las enzimas implicadas son intracelulares. Por lo que la biodegradación requiere la difusión del sustrato desde una fase orgánica a una fase líquida y posteriormente a través de la pared y membrana celular.

La adhesión de las células a la interfase aceite-agua puede reducir al mínimo la distancia de difusión y de este modo facilitar la difusión de sustratos hidrofóbicos en las células. Múltiples factores están implicados en la adhesión, incluidos los factores fisicoquímicos, tales como la carga de superficie de la fase de hidrocarburos, las especies microbianas que dependen de factores como la composición de la superficie celular. La adhesión puede estar afectada también por la presencia de algunas especies químicas en la membrana celular que le confieren un carácter hidrofóbico, además por la presencia de biopolímeros adjuntos que pueden dar adherencia incluso cuando la fuerza electrostática es repulsiva. En el exterior de las células con capacidad para adherirse a compuestos hidrofóbicos se han encontrado lípidos, proteínas y/o oligosacáridos. Otras estructuras extracelulares pueden incluir lipopolisacáridos de membrana externa y proteínas, capas de exopolisacáridos y fimbrias.

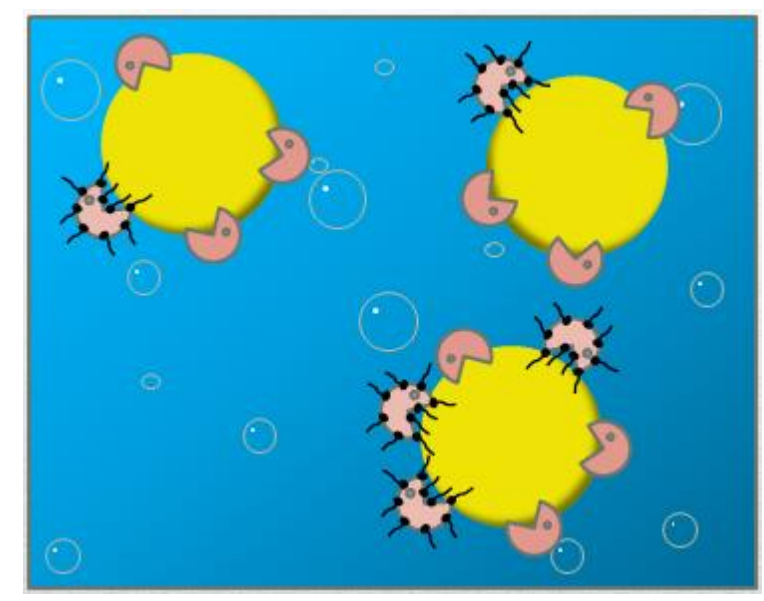

Figura 3.4.4. Consumo bacteriano de HXD por contacto directo

Para promover los mecanismos de consumo, se debe considerar la utilización de un biorreactor que permita tener altas tasas de transferencia de masa facilitando los procesos 
de tratamiento de aguas contaminadas con hidrocarburos $\mathrm{u}$ otros sustratos aceitosos, un biorreactor con estas características es el airlift.

\subsection{Biorreactores airlift}

En recientes décadas el reactor airlift (BAL) ha recibido una mayor atención por parte de las industrias químicas y biotecnológicas. Estos muestran ventajas tales como una construcción simple y bajo consumo de energía asociado con una elevada proporción de transferencia de masa, momento y calor (Chisti, 1989; Jin et al, 2001).

Este biorreactor está provisto de una adecuada capacidad de mezclado logrando una distribución homogénea del oxígeno transferido (y otros nutrientes) en el fluido lo que previene la formación de zonas muertas, en donde puede haber estados anóxicos (Chisti, 1989; Jin et al, 2001).

El reactor airlift está constituido por un cilindro dividido en dos zonas distintas de las cuales sólo una es usualmente alimentada con gas. Las diferencias en la capacidad de retención de la fase gaseosa ( $\mathrm{gg}$ ) continua entre las zonas aireadas y las no aireadas dan como resultado diferentes densidades en estas regiones lo que causa la circulación del fluido en el reactor por la acción del ascenso del gas. La parte del reactor donde se lleva a cabo el ascenso del flujo gas-líquido se denomina "riser" y la región donde se encuentra el descenso del flujo es conocida como "downcomer". Las aplicaciones de los biorreactores airlift dependen de la habilidad para lograr las proporciones requeridas de transferencia de momento, masa y calor con costos de operación aceptables. La viabilidad técnica y económica para el uso de reactores airlift se ha establecido concluyentemente para varios procesos y estos reactores se encuentran en creciente uso en cultivos aerobios, tratamiento de aguas contaminadas y procesos similares. La simplicidad de su diseño y construcción, los modelos de flujo bien definidos y los requerimientos de energía comparativamente bajos para las proporciones requeridas de transporte lo hacen muy atractivo (Chisti, 1989) en relación con los reactores agitados mecanicamente. 
Una dimensión muy importante considerada en estos biorreactores es la relación altura/diámetro (H/D) la cual es típicamente mayor a 6, pero se presentan relaciones superiores en operaciones de tratamiento de agua en donde se tiene una presión hidrostática alta en el fondo de la columna para reforzar el traslado de oxígeno (Camacho et al, 2001). Con la finalidad de obtener una adecuada concentración de oxígeno disuelto y un adecuado coeficiente volumétrico de transferencia de masa $\left(\mathrm{k}_{\mathrm{L}} \mathrm{a}\right)$.

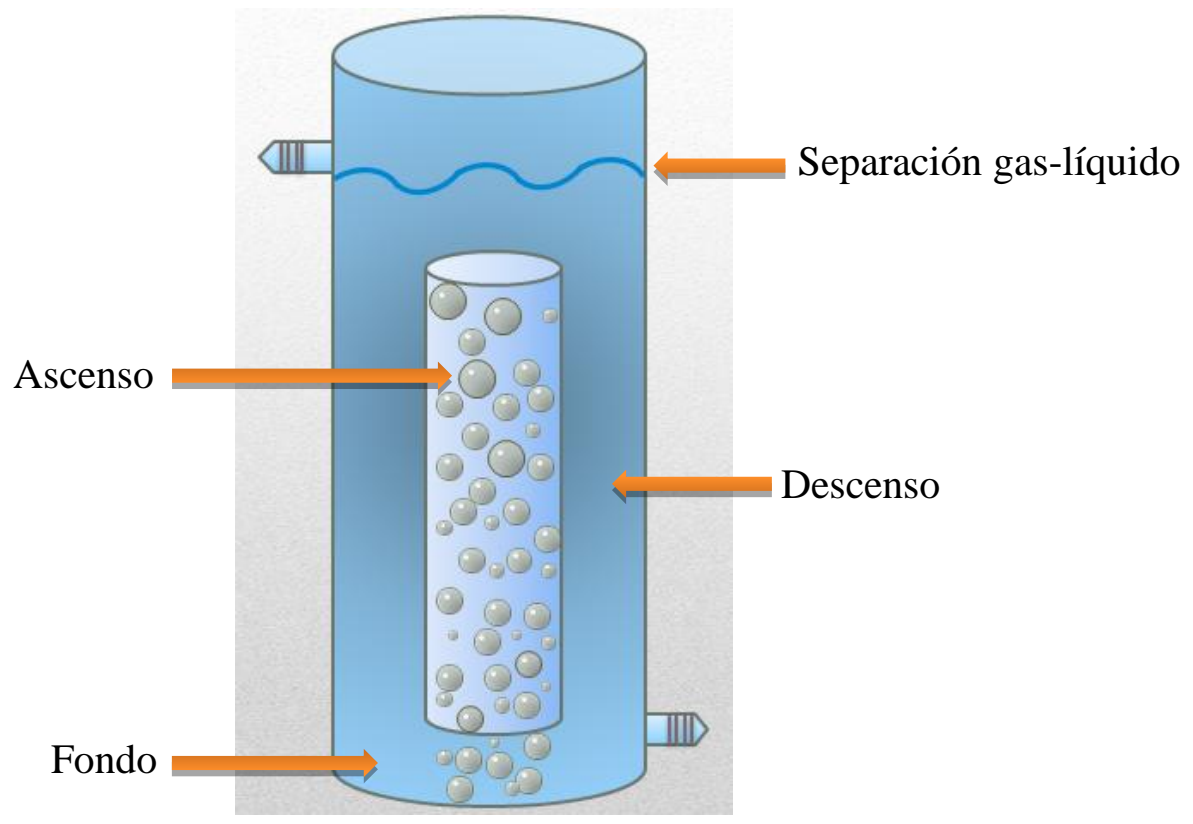

Figura 3.5.1. Biorreactor airlift.

\subsection{Coeficiente volumétrico de transferencia de masa $\left(k_{L} a\right)$ y concentración de oxígeno disuelto}

En los procesos aerobios de tratamiento de aguas la aireación es una operación importante, debido a la baja solubilidad del oxígeno. Este hecho marca pues el tipo de operación ya que el 
oxígeno debe ser suministrado continuamente al cultivo si se desea mantener una población activa, este oxígeno debe transferirse desde la fase gas a la fase líquida, donde puede ser utilizada por los microorganismos. El coeficiente que expresa la capacidad de transferencia de un biorreactor es el coeficiente volumétrico de transferencia de oxígeno, representado como $\mathrm{k}_{\mathrm{L}} \mathrm{a}$. La determinación del valor del coeficiente será pues esencial para evaluar la eficiencia de aireación y cuantificar los efectos que las variables de operación tienen sobre el transporte de oxígeno (Gódia-Casablancas y López-Santín, 1998).

En bioprocesos con alcanos como sustrato, la dificultad de suministrar una cantidad adecuada de oxígeno se ve agravada por la deficiencia de oxígeno en la estructura molecular del sustrato. Esto significa que el requerimiento de oxígeno se ha de cumplir exclusivamente mediante transferencia al cultivo. Este requisito elevado de transferencia de oxígeno en procesos donde se utilizan alcanos en relación con los procesos donde se utilizan carbohidratos, es una característica común del metabolismo de los alcanos independiente de la longitud de la cadena (Clarke y Correia, 2008). 


\section{Definición del problema}

Debido a que las industrias petroleras generan una gran cantidad de aguas residuales que contienen hidrocarburos y estas aguas llegan a ríos, lagos y océanos, deteriorando los ecosistemas, es necesario contar con sistemas de tratamiento de aguas que permitan eliminar los contaminantes hasta su mineralización de forma rápida, eficiente y bajo costo.

Entre estos los sistemas requeridos para el tratamiento de aguas se distinguen los métodos biológicos aerobios que resultan ser, en comparación con los sistemas anaerobios, más eficientes en términos de la energía recuperada por la biomasa por unidad de sustrato procesado; esto genera una cantidad relativamente grande de producción de biomasa o lodo (Droste, 1997), éstas dos importantes características ubican al tratamiento aerobio como el más adecuado para cumplir con los objetivos principales de este trabajo que son, por un lado, la biodegradación eficiente y rápida de los hidrocarburos y por otro, producir una cantidad importante de biomasa, en la modalidad de un consorcio microbiano degradador de hidrocarburos, como un valor agregado al tratamiento del agua contaminada. El consorcio microbiano producido puede ser utilizado para la biorremediación de suelos contaminados con hidrocarburos (Díaz-Ramírez et al, 2004; Medina-Moreno, 2006; Lizardi-Jiménez, 2011). 


\section{Hipótesis}

Aplicar una estrategia de velocidades de aireación variable hace eficiente la depuración de agua contaminada con HXD en un biorreactor del tipo airlift (BAL) en comparación con la velocidad de aireación constante.

\subsection{Hipótesis particular.}

Reinocular el cultivo disminuye el tiempo de tratamiento. 


\section{Objetivos}

\subsection{Objetivo general}

Evaluar las variables de operación que influyen en el consumo de HXD por un consorcio bacteriano en un biorreactor airlift.

\subsection{Objetivos particulares}

1. Evaluar la influencia de la velocidad de aireación sobre el consumo de HXD y producción de sólidos suspendidos.

2. Evaluar el efecto de una reinoculación en el consumo de HXD y producción de sólidos suspendidos.

3. Evaluar el efecto de la disminución de la tensión superficial del medio en el consumo de HXD y la transferencia de oxígeno.

4. Identificar el mecanismo principal de consumo de HXD. 


\section{Estrategia de trabajo experimental}

La estrategia de trabajo experimental se muestra esquemáticamente en la Figura 7.1. Cada una de las etapas se desarrolló como sigue:

1. Se evaluó el efecto de la velocidad de aireación (Ug) en el consumo de HXD para esto se probaron tres Ug: $2.7,0.6$ y $0.37 \mathrm{~cm} \mathrm{~s}^{-1}$, de manera independiente y manteniendo $\mathrm{Ug}$ constante en cada experimento.

2. Se propuso una estrategia de velocidad de aireación variable combinando las 3 velocidades de aireación ensayadas antes.

3. Se realizó una reinoculación del consorcio bacteriano a las 8 horas de tratamiento.

4. Se evaluó la presencia de los surfactantes y la transferencia de oxígeno de la fase gas a la fase líquida. 


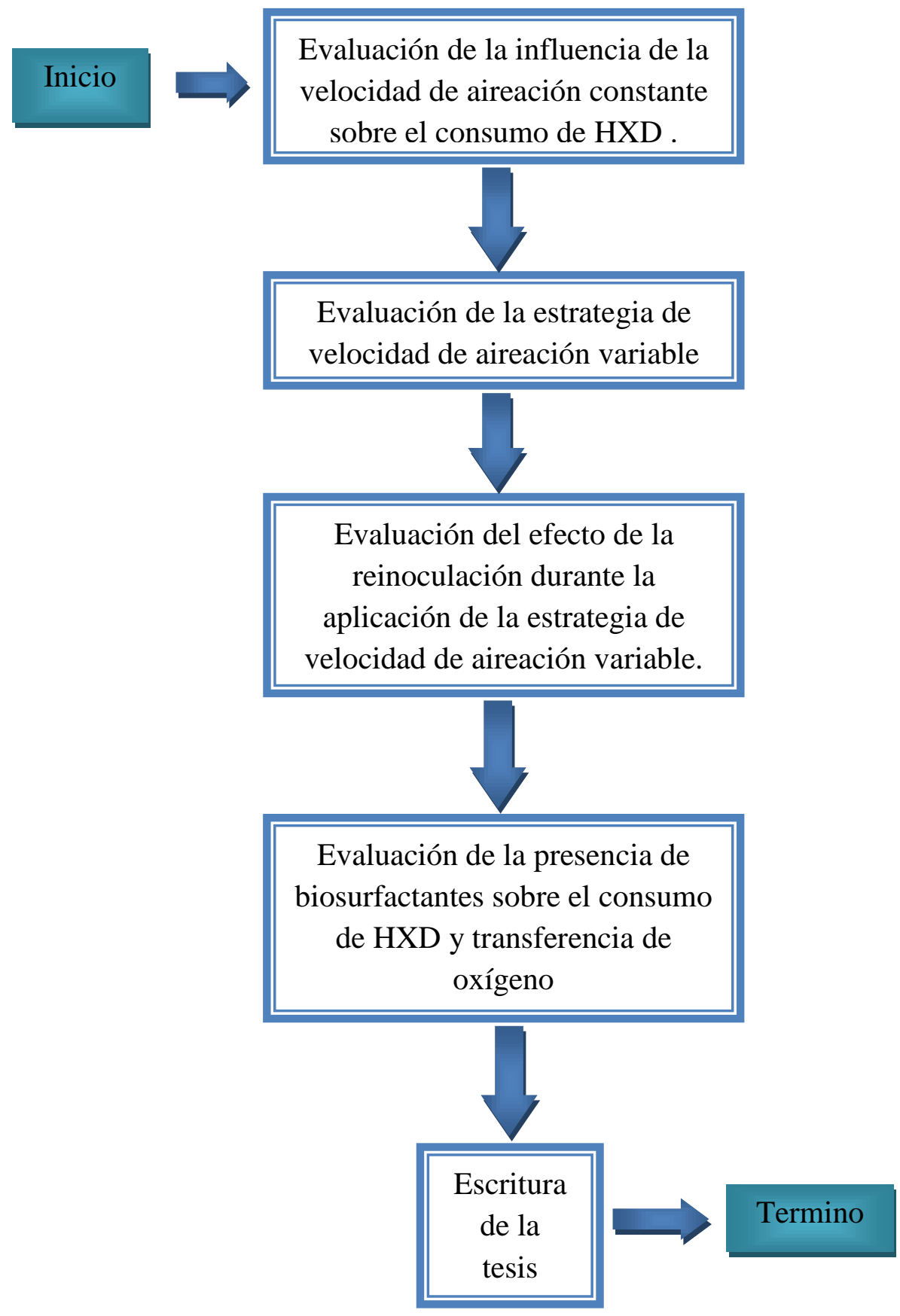

Figura 7.1.1. Síntesis de la estrategia experimental 


\section{Materiales y métodos}

\subsection{Consorcio microbiano biodegradador de hidrocarburos}

El consorcio microbiano utilizado fue aislado en el laboratorio a partir de la rizósfera de Cyperus laxus, planta nativa de pantanos del sureste mexicano, capaz de crecer en suelos contaminados con petróleo (Díaz-Ramírez et al, 2004). La identificación del consorcio se llevó a cabo mediante el análisis y amplificación del gene ribosomal 16s (Tzintzun-Camacho et al, 2012), el consorcio lo constituyen cuatro cepas bacterianas: Xanthomonas sp., Acinetobacter bouvetii, Shewanella sp., Defluvibacter lusatiensis. Para su mantenimiento las cepas fueron resembradas cada 30 días en cajas y tubos con agar soya tripticaseína, y fueron almacenadas a $4{ }^{\circ} \mathrm{C}$.

El inóculo fue preparado utilizando las cuatro cepas que constituyen el consorcio, en una proporción 1:1:1:1. Cada cepa se creció en caldo nutritivo (Bioxon) en un agitador de matraces durante $48 \mathrm{~h}$ a $30^{\circ} \mathrm{C}$ y $200 \mathrm{rpm}$, pasado este tiempo se leyó la absorbancia para cada una de las cepas para conocer la concentración en UFC $\mathrm{mL}^{-1}$ correlacionando con una curva patrón previamente realizada y de esta manera tomar el volumen necesario de cada una para ajustar una concentración de inoculo final de $1.0 \times 10^{5} \mathrm{UFC} \mathrm{mL}^{-1}$ dentro del biorreactor.

Para el experimento de reinoculación se modificó la proporción de las 4 cepas como sigue: 1:50:50:50 para Acinetobacter bouvetii, Xanthomonas sp., Shewanella sp. y Defluvibacter lusatiensis, respectivamente hasta ajustar una concentración de inoculo final $1.0 \times 10^{5}$ UFC $\mathrm{mL}^{-1}$ dentro del biorreactor. La modificación de las proporciones se realizó con la finalidad de disminuir la concentración de Acinetobacter bouvetii, cepa que produce el biosurfactante y aumentar la concentración de las tres cepas restantes, que sospechamos, son las que podrían consumir el biosurfactante y de esta manera dejarían al HXD libre para ser consumido nuevamente por contacto directo. 


\subsection{Medio de cultivo}

Se utilizó medio mineral (Lizardi-Jiménez, 2011) con la siguiente composición $\left(\mathrm{g} \mathrm{L}^{-1}\right)$ : 0.675 NaNO3 (Aldrich, 99.9\% de pureza), 0.215 K2 HPO4 (J. T. Baker 99.3\%), 0.113 KCl (J. T. Baker 99.9\%) y $0.054 \mathrm{MgSO} 4$. (J. T. Baker 100.1\%). A este medio se le adicionaron 1300 ppm de HXD (Sigma Aldrich, 99.9\%). El pH fue ajustado a 6.5 con $\mathrm{HCl} 1 \mathrm{~N}$. Para todas las cinéticas se utilizó 1L de medio mineral con 1300 ppm de HXD (Plaza et al, 2008).

\subsection{Sistema de biorreactores}

El conjunto de biorreactores y los equipos que se emplearon en este estudio se muestran en la Figura 8.3.1.

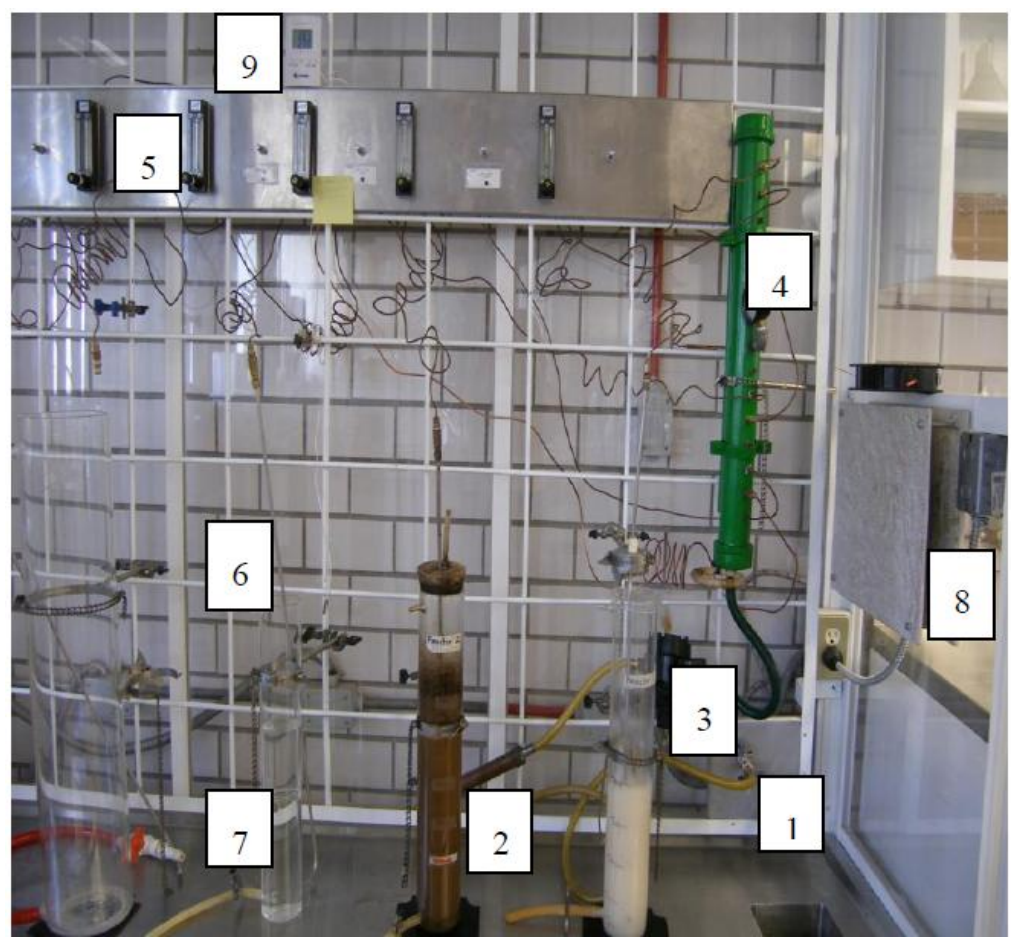

Figura 8.3.1. Sistema de biorreactores.

En donde:

1.- Entrada de aire comprimido para la alimentación a los biorreactores. 
2.- Filtro de aire de cobre relleno de fibra de vidrio y algodón.

3.- Válvula reguladora de presión de entrada de aire, provista de un manómetro, la presión se mantuvo constante $\left(1.6 \mathrm{~kg} \mathrm{~cm}^{-2}\right)$.

4.- Distribuidor general para las líneas de alimentación de aire a los biorreactores, este distribuidor cuenta con un manómetro para registrar la presión de alimentación a los biorreactores $\left(1.6 \mathrm{~kg} \mathrm{~cm}^{-2}\right)$.

5.- Rotámetro, que controla el flujo de aire al biorreactor en particular para cada uno de los ellos.

6.- Distribuidor de aire particular para un biorreactor.

7.- Biorreactor airlift de 1L.

8.- Sistema de control de temperatura provisto de un sensor que activa o desactiva una resistencia y un pequeño ventilador para homogeneizar el calor en la vitrina.

9.- Termómetro.

\subsection{Biorreactor utilizado}

El biorreactor utilizado fue un airlift (BAL) cilíndrico construido en vidrio Pyrex con un tubo concéntrico y un volumen de $1 \mathrm{~L}$ de operación. El BAL fue operado en lotes a $30^{\circ} \mathrm{C}$ siguiendo dos estrategias de aireación diferentes: (i) tres velocidades constantes de aireación (2.7, 0.6 y $0.37 \mathrm{~cm} \mathrm{~s}^{-1}$ ) y (ii) la combinación de las mismas como sigue: se aplicó la velocidad de $2.7 \mathrm{~cm}$ $\mathrm{s}^{-1}$ durante $5 \mathrm{~h}$, posteriormente se redujo la velocidad de aireación a $0.6 \mathrm{~cm} \mathrm{~s}^{-1}$ y se mantuvo durante $5 \mathrm{~h}$ más, finalmente se aplicó la velocidad de $0.37 \mathrm{~cm} \mathrm{~s}^{-1}$ hasta el final de la cinética, esto en lotes de $46 \mathrm{~h}$; inoculados con las cuatro cepas que conforman el consorcio guardando una proporción de 1:1:1:1, excepto en el caso de la aplicación de la reinoculación que fue de 1:50:50:50 para Acinetobacter bouvetii, Xanthomonas sp., Shewanella sp. y Defluvibacter 
lusatiensis, respectivamente, pero siempre a una concentración inicial de inóculo total de 1.0 $\mathrm{X} 10^{5} \mathrm{UFC} \mathrm{mL} \mathrm{L}^{-1}$.

\subsection{Evaluación del consumo de HXD}

Para la determinación de la concentración residual de HXD en el medio de cultivo y para cada tiempo se llevó a cabo una extracción líquido-líquido $(1: 1 \mathrm{v} / \mathrm{v})$ con una mezcla hexano acetona $(1: 1 \mathrm{v} / \mathrm{v})$. La fase orgánica se analizó por cromatografía de gases previa correlación con una curva estándar, utilizando un cromatógrafo Modelo 3900, Varian, USA empleando un detector FID a $300{ }^{\circ} \mathrm{C}$, columna DB-Petro narrow bore, J \& W Scientific de $30 \mathrm{~m}$ x $0.25 \mathrm{~mm}$ y helio como gas acarreador. La temperatura del inyector y detector permanecieron constantes a $290^{\circ}$ y $300^{\circ} \mathrm{C}$, respectivamente. El programa de temperatura fue diseñado como sigue: 120 (1 min), $10^{\circ} \mathrm{C} \mathrm{min}^{-1}$ hasta $150{ }^{\circ} \mathrm{C}(2 \mathrm{~min}), 15^{\circ} \mathrm{C} \mathrm{min}^{-1}$ hasta $170{ }^{\circ} \mathrm{C}(1.5 \mathrm{~min})$.

\subsection{Sólidos suspendidos}

La cuantificación de sólidos suspendidos (SS), que contienen al consorcio microbiano degradador de petróleo y los surfactantes, se realizó por gravimetría como sigue: al final de la cinética se tomaron $200 \mathrm{~mL}$ de muestra por triplicado, se centrifugaron a $2000 \mathrm{rpm} 4^{\circ} \mathrm{C}$ durante $30 \mathrm{~min}$, se desechó el sobrenadante, y el precipitado se colocó en recipientes de aluminio previamente puestos a peso constante y se pusieron a secar en estufa a $60^{\circ} \mathrm{C}$ hasta obtener peso constante.

\subsection{Tensión superficial}

La tensión superficial en la fase líquida durante la cinética se determinó utilizando un tensiómetro (Fisher Manual Surface Tensiometer Model 20, Fisher Scientific International, Wisconsin, USA). Para esta medición se utilizaron $7 \mathrm{~mL}$ de muestra sin tratamiento previo. 


\subsection{Micrografías}

Se tomaron micrografías de los tiempos más relevantes del cultivo (al inicio en que se presenta la zona de estancamiento) alrededor de las $8 \mathrm{~h}$ de tratamiento, al finalizar la zona de estancamiento (alrededor de las $20 \mathrm{~h}$ de tratamiento) y al final del tratamiento. Estas imágenes se obtuvieron a partir de $1 \mathrm{~mL}$ de muestra adicionado con $1 \mu \mathrm{L}$ de rodofila, carotenoide hidrofóbico que tiñe al HXD, posteriormente se adicionaron $5 \mu \mathrm{L}$ de azul de metileno con la finalidad de teñir las células; de esta mezcla se colocó una gota en un porta-objetos y se observó al microscopio; las fotografías se tomaron con el objetivo de inmersión en aceite (100X).

\subsection{Coeficiente volumétrico de transferencia de oxígeno}

Se llevó a cabo la evaluación de $\mathrm{k}_{\mathrm{L}}$ a por la técnica dinámica (Fujio et al, 1973), utilizando un electrodo de oxígeno disuelto (Aplisens, USA).

\subsection{Análisis estadístico.}

Durante las cinéticas se tomaron muestras por triplicado, los valores graficados corresponden al promedio de las tres lecturas en donde las barras de error representan el error estándar. Para hacer una comparación de las cinéticas se utilizó un programa estadístico (SPSS) ajustando un modelo polinomial de orden 5 en donde los coeficientes obtenidos para cada una de las cinéticas a comparar se les realizó una prueba $t$ de student para determinar, con un $95 \%$ de confianza, si eran iguales o diferentes. 


\section{Resultados y discusión}

\subsection{Cinéticas de consumo de HXD a velocidades de aireación constante}

Este experimento se realizó para conocer la influencia de la velocidad de aireación ( $\mathrm{Ug}$ ) constante sobre el consumo de HXD y encontrar la velocidad de aireación a la cual se alcanza la concentración de HXD que establece la norma de $40 \mathrm{mg} \mathrm{L}^{-1}$ de hidrocarburos totales de petróleo (NOM-143-SEMARNAT-2003) en el menor tiempo de operación. En la Figura 9.1.1 se muestran las cinéticas realizadas con las tres $U g$ ensayadas $\left(2.7,0.6\right.$ y $\left.0.37 \mathrm{~cm} \mathrm{~s}^{-1}\right)$.

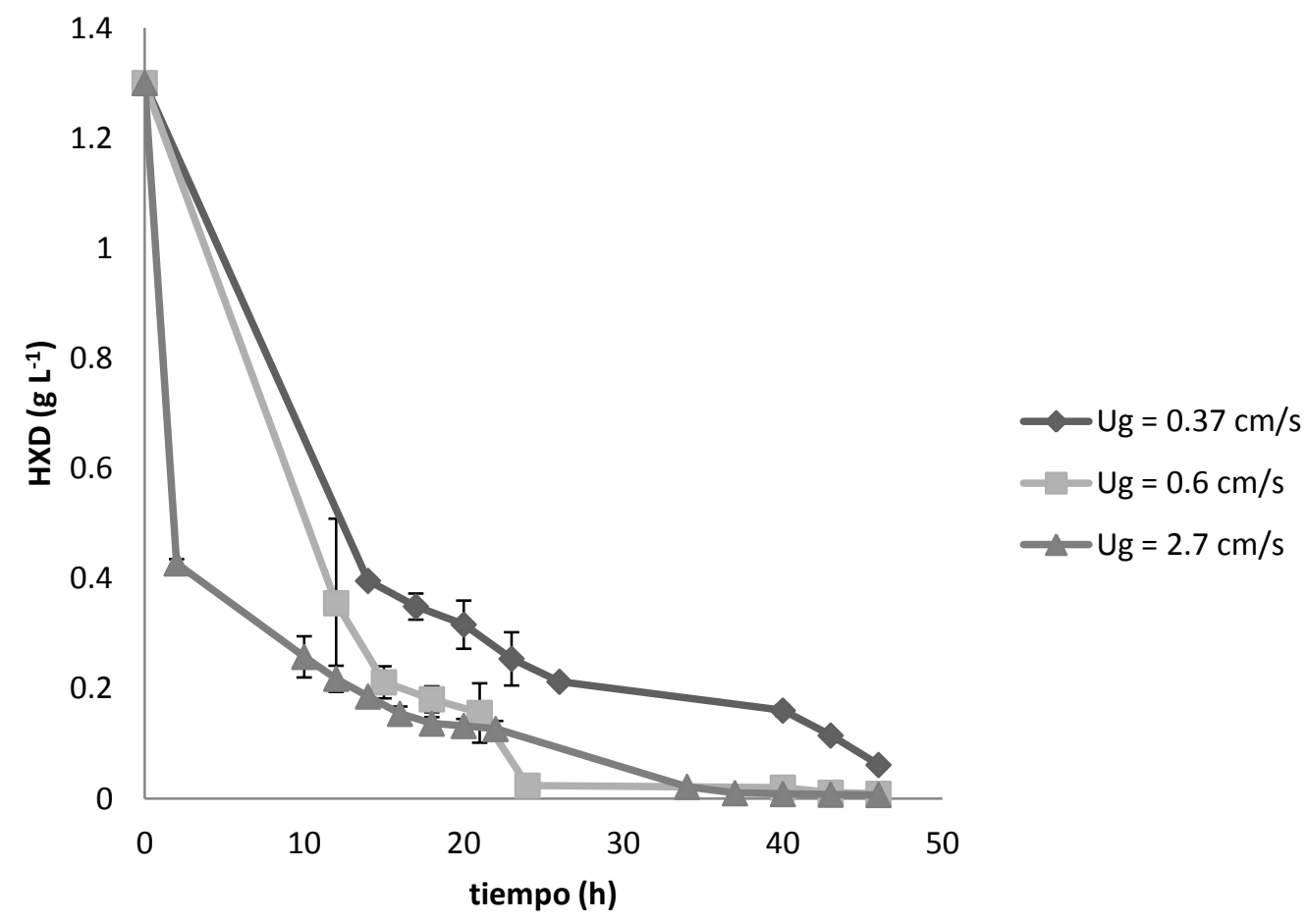

Figura 9.1.1 Cinéticas de consumo de HXD a diferentes velocidades de aireación 
En la Figura 9.1.1 se observa, para todas las cinéticas, tres etapas características del cultivo, una de consumo rápido de HXD seguida de una segunda etapa de estancamiento en el consumo y finalmente una tercera en donde se observa la restitución del consumo de HXD. Se observa también que a velocidades de aireación mayor la biodegradación de HXD es más rápida, principalmente durante las primeras horas de cultivo. Sin embargo, en la primera etapa no se puede asegurar que el consumo sea directamente proporcional al aumento de velocidad de aireación, como se esperaba, ya que para las cinéticas con $U g$ de 0.6 y $0.37 \mathrm{~cm} \mathrm{~s}^{-1}$ no fue posible analizar muestras para las primeras horas ya que en cinéticas preliminares se observó una dispersión grande en los datos de consumo de HXD, posiblemente debido a la baja solubilidad del HXD que se encuentra en el orden de $10^{-7} \mathrm{mg} \mathrm{L}^{-1}$, de tal manera que durante las primeras horas del cultivo no se observaría una buena dispersión de la fase orgánica (HXD) en la fase acuosa del medio de cultivo sino hasta la aparición de biosurfactantes. Bouchez-Naitali y Vandecasteele en el 2008 mencionan que los biosurfactantes pueden dispersar los hidrocarburos en el medio e incluso modificar la superficie celular haciéndolas más hidrofóbicas con lo que adquieren capacidad para interactuar con el HXD, incrementando su biodisponibilidad. Así, no se puede asegurar que con la aplicación de $U g$ de $2.7 \mathrm{~cm} \mathrm{~s}^{-1}$ se obtenga una degradación de HXD más rápida que con las velocidades de 0.6 y $0.37 \mathrm{~cm} \mathrm{~s}^{-1}$ pero se puede inferir, de acuerdo a los resultados obtenidos por Lizardi-Jiménez et al, (2012), que la biodegradación se favorece conforme aumenta la velocidad de aireación ya que ellos encuentran que a mayores velocidades de aireación se favorece la transferencia de HXD por un aumento en el área específica de transferencia, y se favorece también la transferencia de oxígeno. Nuestros resultados sugieren que a la más alta velocidad de aireación $\left(2.7 \mathrm{~cm} \mathrm{~s}^{-1}\right)$ la tasa de consumo es también mayor, al menos, durante las primeras $10 \mathrm{~h}$ de cultivo, con respecto a las otras velocidades de aireación ensayadas.

En la Figura 9.1.1; también se observa que con una velocidad de aireación constante de 0.6 $\mathrm{cm} \mathrm{s}^{-1}$ se llega a la concentración de HXD dentro de normas de $40 \mathrm{mg} \mathrm{L}^{-1}$ (alrededor de las 25 h) más rápidamente que con la $\mathrm{Ug}$ de $2.7 \mathrm{~cm} \mathrm{~s}^{-1}$ (alrededor de las 35 h). Con la velocidad de aireación mayor $\left(2.7 \mathrm{~cm} \mathrm{~s}^{-1}\right)$ se esperaba una reducción de HXD más rápida ya que de acuerdo a lo reportado velocidades de aireación mayores favorecen la transferencia de masa; sin embargo, en otros trabajos con sistemas similares (Ochieng, et al, 2002; Ochieng et al, 2003) 
se prueba que al aumentar la velocidad de aireación la biodegradación disminuye debido a la presencia de un efecto de coalescencia de las burbujas de aire que reduce la transferencia de masa.

En la primera etapa el rápido consumo de HXD podría ser provocado por el aumento de la población inicial de bacterias ya que de acuerdo a Tzintzun-Camacho et al 2012 en donde evalúan el crecimiento de las bacterias que conforman el consorcio utilizado en este trabajo consumiendo HXD con una concentración inicial 10 veces mayor que la utilizada para nuestro caso encuentran un rápido crecimiento de bacterias para los primeros días de cultivo, con estos antecedentes se puede sugerir el aumento de la población de bacterias durante las primeras horas y en consecuencia se presentaría un consumo rápido de sustrato (HXD), estos resultados son comparables con los obtenidos por Ochieng et al, 2003 en donde evaluaron la degradación de materia orgánica (DQO) de agua proveniente de una refinería, de una cervecería y de la mezcla de ambas aguas encontrando para todos los casos una etapa de consumo rápido de materia orgánica debido al aumento de biomasa. En el trabajo de Ochieng et al, 2003 al periodo de rápida reducción de la DQO le sigue una tercera etapa en la cual la tasa de consumo disminuye de manera análoga a la que se muestra en la Figura 9.1.1 estos autores atribuyen la presencia de esta zona al agotamiento de los nutrientes y mencionan que también puede deberse a la formación de DQO inerte como resultado de la actividad metabólica de los microorganismos. En el presente trabajo no se analizó la DQO, sin embargo, es posible suponer la aparición de productos derivados del metabolismo. Estos metabolitos no se espera que sean inertes pero si se espera que tengan algún efecto en el consumo de HXD durante un periodo de entre 6 y $10 \mathrm{~h}$, coincidiendo con la zona de no consumo de HXD o zona de estancamiento en el consumo de HXD. Estos posibles metabolitos podrían corresponder a los biosurfactantes que, se sabe (Tzintzun-Camacho et al 2012), producen al menos una de las cepas del consorcio (Acinetobacter bouvetii). Los biosurfactantes podrían estar formando emulsiones estables dificultando la transferencia de masa e incluso podrían constituir una fuente de carbono preferencial para las bacterias del consorcio, de tal manera que el HXD pasaría ser, al menos durante esta etapa del cultivo, una fuente de carbono alterna. Los sólidos suspendidos (SS), que incluyen a la biomasa y exopolímeros, se midieron al final del cultivo (46 h) y no antes debido a que la baja concentración de estos en los primeros tiempos medidos 
en la cinética no permitieron llevar a cabo mediciones por gravimetría. Los resultados que se muestran en la Tabla 9.1.1 incluyen la desviación estándar de 3 repeticiones en donde no se observan diferencias significativas.

Tabla 9.1.1. Producción de sólidos suspendidos (SS) a las 46 h de cultivo para las cinéticas de aireación constantes.

\begin{tabular}{cc}
\hline $\mathrm{Ug}\left(\mathrm{cm} \mathrm{s}^{-1}\right)$ & Producción de SS $\left(\mathrm{g} \mathrm{L}^{-1}\right)$ \\
\hline 2.7 & $0.22 \pm 0.013$ \\
0.6 & $0.20 \pm 0.009$ \\
0.37 & $0.19 \pm 0.018$ \\
\hline
\end{tabular}

Estos resultados pueden deberse a que con las 3 velocidades ensayadas se logró la misma concentración final de HXD (medido a las 46 h), con los mismos rendimientos finales (base sustrato consumido) independientemente de la velocidad de aireación constante, aunque para la velocidad de aireación de $0.37 \mathrm{~cm} \mathrm{~s}^{-1}$ se necesitó más tiempo probablemente debido a que una velocidad de aireación baja provoca una deficiente dispersión de los hidrocarburos (Vinod y Reddy, 2006).

Estos resultados son diferentes a los obtenidos por Lizardi-Jiménez et al, 2012 ya que ellos encuentran que la producción de SS es proporcional al aumento de velocidad de aireación, en un biorreactor airlift, una concentración inicial de HXD de $13 \mathrm{~g} \mathrm{~L}^{-1}$ y las velocidades ensayadas fueron 2.7 esta discrepancia puede explicarse debido a que estos autores encuentran también una relación entre la velocidad de aireación y el consumo de HXD durante las cinéticas, sin embargo para este trabajo la relación entre el consumo de HXD y la velocidad de aireación sólo se observa para las primeras 10-12 horas. 
A partir de estos resultados se planteó la hipótesis de que una estrategia de velocidades de aireación variable incidiría en el consumo de HXD eliminando o minimizando la etapa de estancamiento.

\subsection{Cinéticas de consumo de HXD a velocidad de aireación variable}

Con la finalidad de probar la hipótesis de que la combinación de velocidades de aireación resultaba mejor, en términos de eficiencia, que la estrategia de aireación constante y con la expectativa de eliminar o disminuir la zona de estancamiento de consumo de HXD, se aplicó una estrategia de Ug variable como sigue: el cultivo se inició aplicando $2.7 \mathrm{~cm} \mathrm{~s}^{-1}$ durante las primeras 5 horas permitiendo con esto tener un medio más homogéneo al inicio, posteriormente $0.6 \mathrm{~cm} \mathrm{~s}^{-1}$ durante 5 horas más, considerando que en este tiempo el medio es más homogéneo por la posible presencia de los biosurfactantes y que no se requeriría una elevada velocidad de aireación; finalmente, después de 10 horas de iniciado el cultivo, se aplicó una velocidad de $0.37 \mathrm{~cm} \mathrm{~s}^{-1}$ hasta el final del tratamiento. En la Fig. 9.2.1 se muestra la comparación de la cinética realizada con velocidad de aireación variable y la cinética realizada con velocidad de aireación constante de $2.7 \mathrm{~cm} \mathrm{~s}^{-1}$. Se observa un comportamiento semejante en ambas cinéticas: una zona de consumo rápido de HXD que va decreciendo a partir de las tres horas de tratamiento hasta llegar a una zona de estancamiento de consumo que se prolonga alrededor de diez horas. Posteriormente, se identifica otra zona en la que el HXD es consumido hasta que se agota. Para las condiciones ensayadas se observa que las velocidades de aireación no tienen efecto sobre el consumo de HXD, esto representa un beneficio práctico para el proceso (ahorro de energía y costos) ya que aplicando bajas velocidades de aireación se obtienen los mismos resultados que aplicando una alta velocidad constante de $2.7 \mathrm{~cm} \mathrm{~s}^{-1}$.

Nuestros resultados no coinciden con lo reportado por Lizardi-Jiménez et al, 2012 en donde ellos encuentran que el cambio de velocidad de aireación sí tiene efecto sobre el consumo de HXD, realizan un experimento en un biorreactor de $1 \mathrm{~L}$ con medio mineral y HXD como fuente de carbono, a una concentración de $13 \mathrm{~g} \mathrm{~L}^{-1}$ utilizando un consorcio bacteriano constituido por cuatro cepas, la cinética comienza con una velocidad de aireación de $0.61 \mathrm{~cm}$ 
$\mathrm{s}^{-1}$ a los 3 días de cultivo se aplica una aireación de $2.7 \mathrm{~cm} \mathrm{~s}^{-1}$ esta cinética es comparada con una cinética realizada a velocidad constante de $0.61 \mathrm{~cm} \mathrm{~s}^{-1}$ y encuentran que aplicando la estrategia de velocidad de aireación variable el consumo de HXD es más rápido a partir del tercer día.

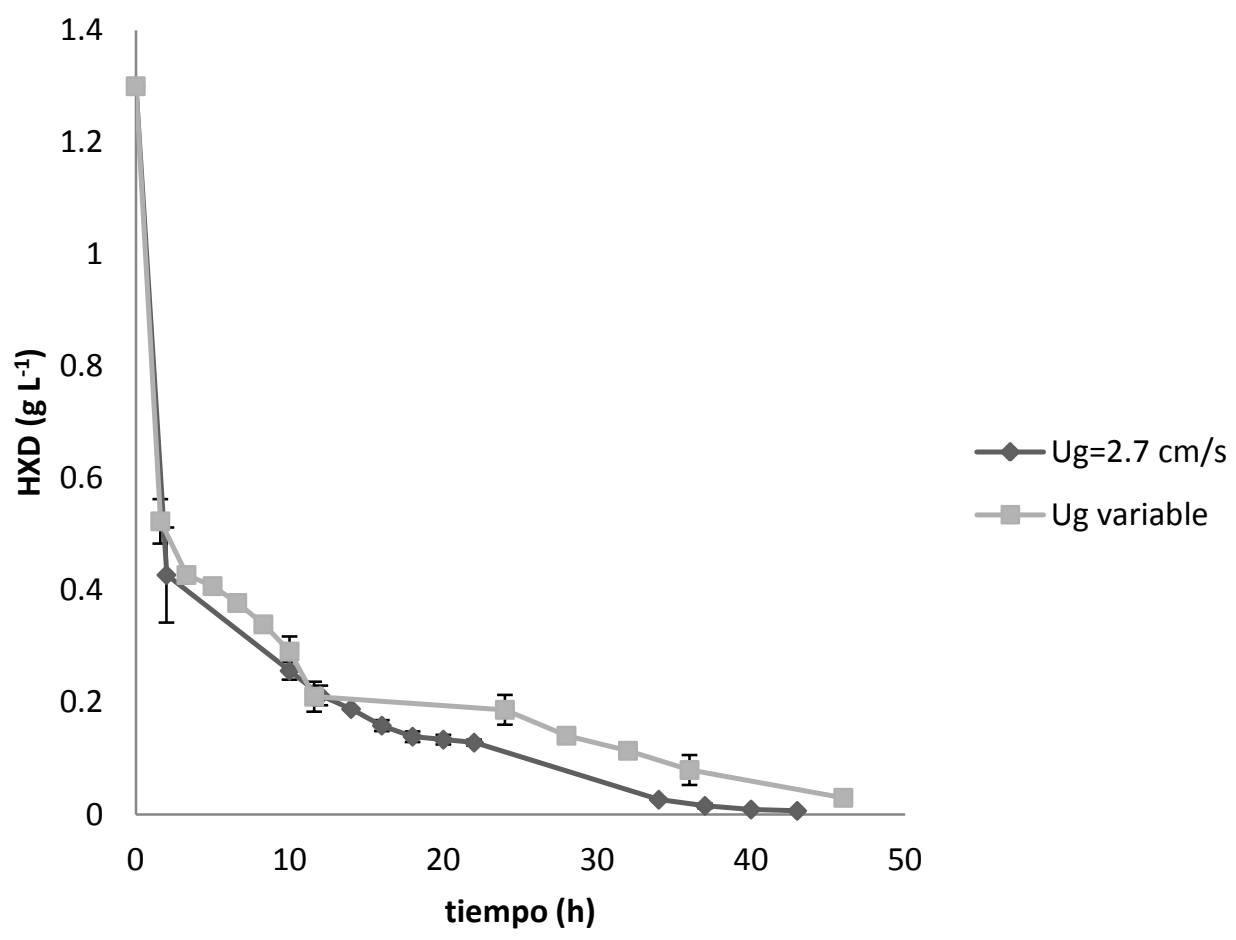

Figura 9.2.1. Cinéticas de consumo de HXD con Ug constante $2.7 \mathrm{~cm} \mathrm{~s}^{-1}$ y con velocidad de aireación variable $\left(2.7 \mathrm{~cm} \mathrm{~s}^{-1}, 5 \mathrm{~h} ; 0.6 \mathrm{~cm} \mathrm{~s}^{-1}, 5 \mathrm{~h}: 0.37 \mathrm{~cm} \mathrm{~s}^{-1}, 15 \mathrm{~h}\right)$.

La discrepancia podría explicarse por la diferencia de concentraciones iniciales de HXD. En nuestro caso en el momento que ocurre el cambio de aireación la concentración de HXD es ya muy baja (alrededor de $\left.0.2 \mathrm{~g} \mathrm{~L}^{-1}\right)$ con respecto a la inicial $\left(1.3 \mathrm{~g} \mathrm{~L}^{-1}\right)$ por lo que el cambio en la velocidad de aireación ya no tiene efecto. Se midieron los sólidos suspendidos (SS) a las $46 \mathrm{~h}$ para saber si la estrategia de velocidad de aireación variable tenía efecto sobre la producción en comparación con los tratamientos de aireación constante para lo cual no se encontraron diferencias ya que la producción fue de $0.19 \pm 0.02 \mathrm{gL}^{-1}$. 
Finalmente, analizando los resultados se observa que a partir de alrededor de las 10 horas de tratamiento el consumo de HXD es independiente de la velocidad de aireación esto mismo se corrobora al observar las tasas de consumo de HXD calculadas para las cinéticas a Ug constantes y Ug variable que se muestran en la Figura 9.2.2. Las tasas de consumo se calcularon como el cociente de las diferencias de HXD consumido entre las diferencias de tiempo en que ocurre el consumo.

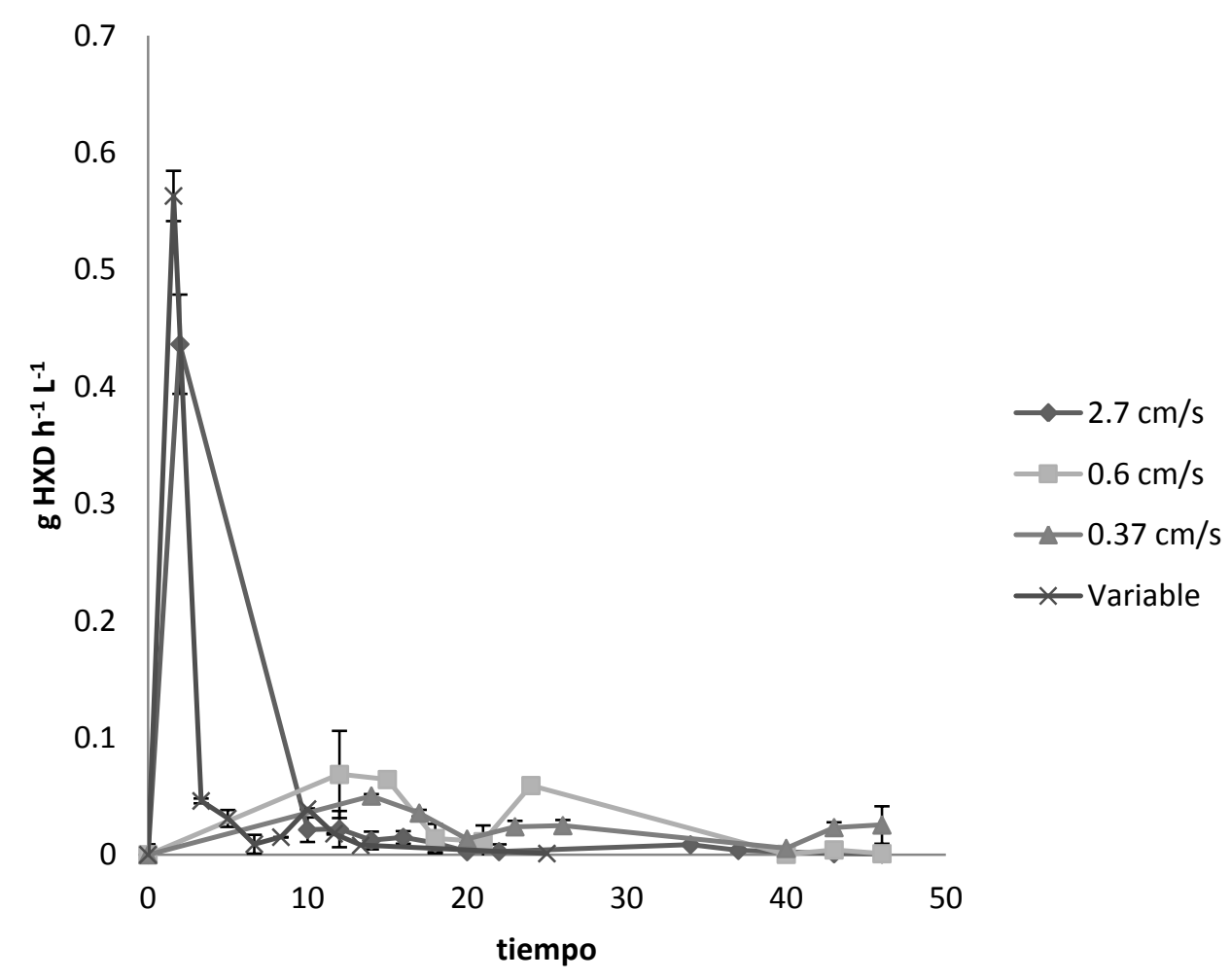

Figura 9.2.2. Tasas de consumo de HXD para cada tiempo a Ug constantes y variable.

Para todas las cinéticas se observa una mayor tasa de consumo durante las primeras horas; se observa también que a menor $\mathrm{Ug}$ se tienen menores tasas de consumo durante las primeras horas. Las tasas de menor consumo de HXD corresponden, en todas las cinéticas al momento en que se llega a una concentración de alrededor de $0.2 \mathrm{~g} \mathrm{~L}^{-1}$ (ver Figura 9.2.1), i.e., la etapa 
de estancamiento de HXD. Esto sugiere que: (i) a esa concentración se presentan problemas con la transferencia de masa ya sea del oxígeno, de los hidrocarburos o de ambos; (ii) que durante esta etapa se consumen preferentemente intermediarios oxidados del HXD que podrían ser biosurfactantes y (iii) que al agotarse la fuente de carbono preferencial se restituye el consumo del HXD lo cual explicaría el aumento de la tasa de consumo después de ser prácticamente cero.

Nuestros resultados sugieren que la tasa de consumo de HXD no depende de la velocidad de aireación pero sí podría depender de al menos uno de los siguientes factores:

i. La falta de un número importante de células que consuman HXD además de otra posible fuente de carbono preferencial, es decir, una limitación biológica.

ii. La biodisponibidad del HXD en el medio, i.e. está presente pero en forma emulsificada y no biodisponible para el consorcio por el efecto de los biosurfactantes producidos por las bacterias del consorcio.

iii. La presencia de biosurfactantes provoca una baja transferencia de oxígeno disuelto, es decir, existe una limitación de oxígeno.

iv. La presencia de otra fuente de carbono preferencial parcialmente oxidada, derivada del HXD, como por ejemplo los biosurfactantes.

Las primeras 3 posibles causas de la presencia de la zona de estancamiento se probaron en este trabajo. La última posibilidad que se refiere al consumo preferencial de otra fuente de carbono derivada del HXD como los biosurfactantes no se ensayó en este trabajo, sin embargo en trabajos previos realizados en el laboratorio (Tzintzun-Camacho et al, 2012) se observaron indicios claros del consumo de los biosurfactantes cuando se utilizaron como única fuente de carbono y energía en cultivos agitados de las 4 cepas que conforman el consorcio: Acinetobacter bouvetii y Defluvibacter lusatiensis fueron capaces de crecer a expensas de los biosurfactantes. 


\subsection{Efecto del aumento de células: reinoculación.}

Para corroborar si el reactor se encontraba limitado biológicamente se realizó una nueva cinética con reinoculación a las ocho horas de cultivo, al inicio de la etapa de estancamiento de consumo, en la Figura 9.3.1 se muestra el efecto de la reinoculación.

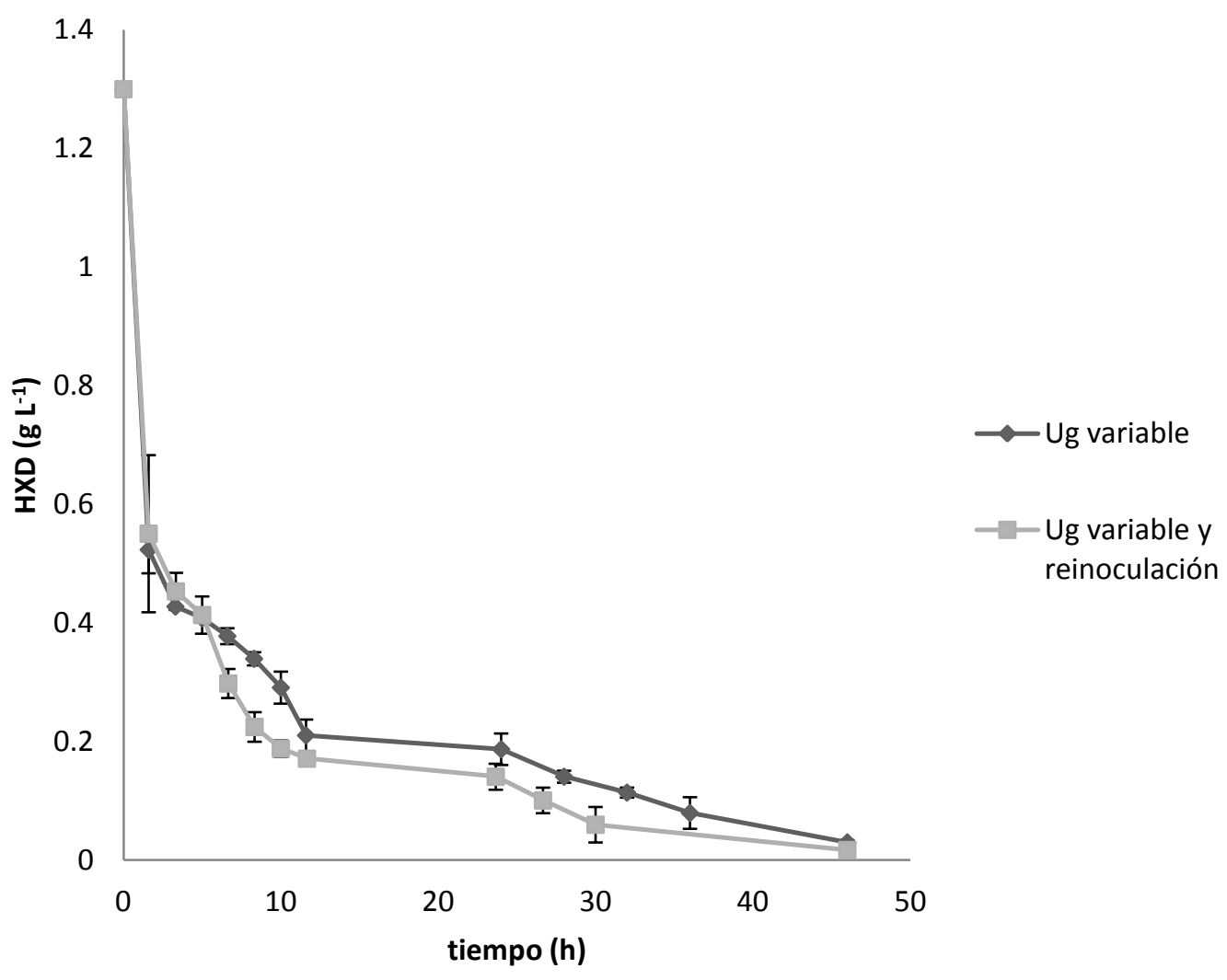

Figura 9.3.1. Cinéticas de consumo de HXD aplicando velocidad variable de aireación y velocidad variable más reinoculación a las $8 \mathrm{~h}$ de iniciado el cultivo.

En la Figura 9.3.1 se observa que al reinocular no se elimina ni se reduce la etapa de estancamiento de consumo de HXD. Las dos cinéticas mostradas no son significativamente diferentes con una confianza del $95 \%$. Se pueden distinguir las mismas tres etapas características detalladas antes. Esta inesperada respuesta podría deberse a que la reinoculación se realiza justo cuando inicia la etapa de estancamiento que pudiera 
corresponder con la máxima concentración de biosurfactantes en el medio así las bacterias reinoculadas consumirían también esta fuente de carbono; sin embargo, se esperaría que al haber una mayor población de bacterias que consuman los biosurfactantes estos se agotarían más rápidamente disminuyendo así la etapa de estancamiento de consumo; esto no sucede. Estas observaciones permiten suponer que los biosurfactantes o intermediarios de la degradación de HXD constituyen una importante fuente de almacenamiento de sustrato. Recientemente, (Lin et al, 2010) se reportó en bacterias el efecto de la concentración del inóculo inicial sobre la degradación de naftaleno encontrando un aumento significativo en la degradación correspondiente al aumento de la concentración de inóculo. En nuestro trabajo, aunque la proporción de las poblaciones del reinoculo se modificó con la intención de incrementar a las poblaciones que consumen biosurfactantes y disminuir a la que los produce, se demostró que la concentración del inóculo y la variante ensayada no tuvo ningún efecto en la degradación de HXD. Estos resultados se corroboraron al comparar las tasas de consumo de HXD mostradas en la Figura 9.3.2.

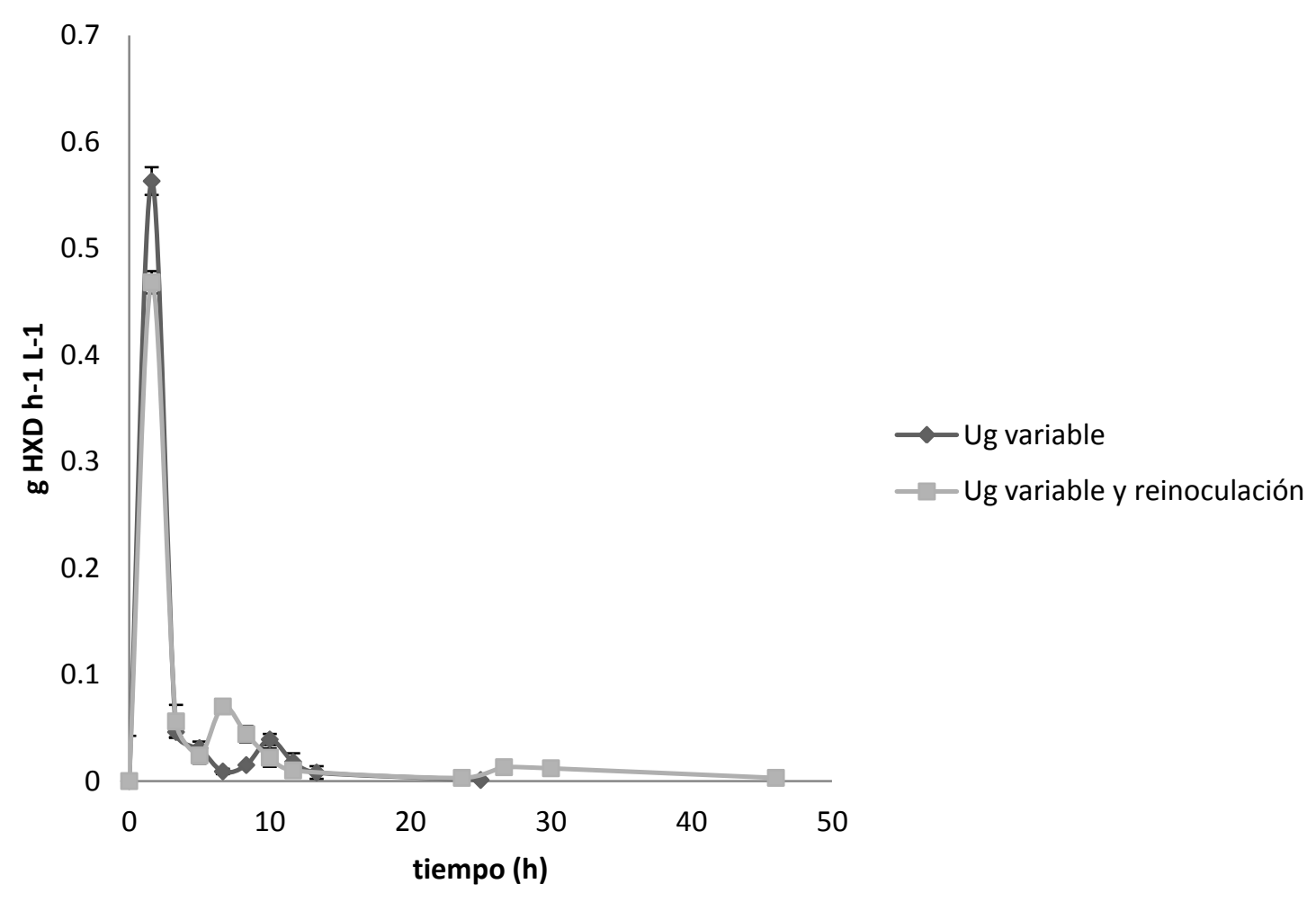

Figura 9.3.2. Comparación de las tasas de consumo a Ug variable con y sin reinoculación 
Nuestros resultados sugieren que la reinoculación no tiene el efecto esperado ya que las dos cinéticas de tasas de consumo no son significativamente diferentes. La producción de sólidos suspendidos (SS), al final del cultivo con reinoculación fue de $0.18 \pm 0.022 \mathrm{~g} \mathrm{~L}^{-1}$, igual a los producidos en las cinéticas con Ug constantes, ya que aunque se aumentó el inoculo y se modificó la aireación, la concentración de sustrato fue la misma.

Con la hipótesis de que los biosurfactantes producidos por el consorcio se acumulan durante la etapa de estancamiento y que el consumo de los biosurfactantes podría estar limitado por la transferencia de oxígeno o bien que los biosurfactantes acumulados podrían constituir una barrera difusional que limitara la transferencia de oxígeno a las células (Asgharpour et al 2010), se realizó la medición de la tensión superficial para corroborar su presencia.

\subsection{Efecto de la presencia de biosurfactantes.}

Para probar la hipótesis de que la presencia de biosurfactantes podría estar afectando el consumo de HXD se midió la tensión superficial en una nueva cinética especialmente durante la etapa de estancamiento del consumo de HXD. En la Figura 9.4.1 se muestra la variación de la concentración de HXD y la tensión superficial expresada en Din $\mathrm{cm}^{-1}$ con respecto al tiempo, para una estrategia de $\operatorname{Ug}$ variable $\left(2.7 \mathrm{~cm} \mathrm{~s}^{-1}, 5 \mathrm{~h} ; 0.6 \mathrm{~cm} \mathrm{~s}^{-1}, 5 \mathrm{~h} ; 0.37 \mathrm{~cm} \mathrm{~s}^{-1}, 26 \mathrm{~h}\right)$ 


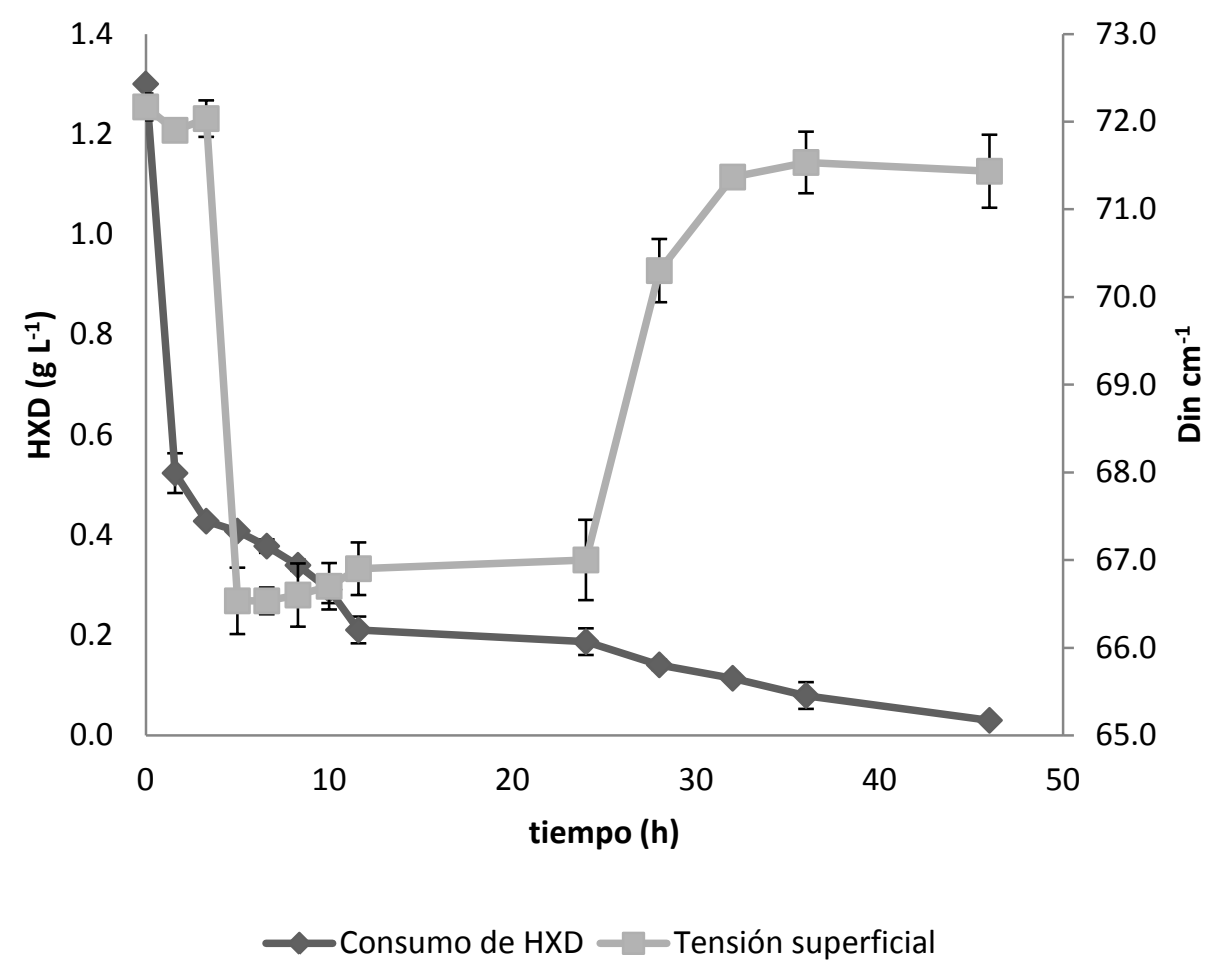

Figura 9.4.1. Tensión superficial obtenida durante la cinética a Ug variable.

En la Figura 9.4.1 se aprecia una primera etapa en donde la tensión superficial disminuye coincidiendo con el consumo rápido de HXD. Posiblemente debido a que el HXD se transforma rápidamente en biosurfactantes y por eso no se detecta. El valor más bajo para la tensión superficial se mantiene constante a lo largo de la etapa de estancamiento. Este resultado sugiere que la formación de emulsiones estables podría impedir el acceso de las bacterias al HXD. A partir de las $25 \mathrm{~h}$ se presenta un aumento en la tensión superficial asociado a una nueva y muy clara disminución en la concentración de HXD esto sugiere que a partir de este momento las emulsiones producidas pierden la estabilidad debido al consumo de los biosurfactantes dejando así al hidrocarburo libre haciendo suponer que el consumo cuantitativamente más importante del HXD se realiza a través de las formas libres, insolubles y parcialmente dispersas en el medio de cultivo. Zhao et al en el 2011 mencionan que en presencia de surfactantes químicos como el Tween 80 se inhibe la biodegradación de 
fenantreno por parte de dos cepas bacterianas, Bacillus subtilis y Pseudomona aeruginosa, debido al secuestro de los hidrocarburos en micelas que provocan una baja biodisponibilidad, mencionan, además, que los surfactantes pueden ser consumidos preferentemente o pueden llegar a ser tóxicos para los microorganismos.

En nuestro trabajo, los biosurfactantes producidos aparentemente no tienen mucho efecto sobre la tensión superficial ya que sólo desciende de 73.1 a 65 Din $\mathrm{cm}^{-1}$, mientras que Khopade et al en el 2012 indican que los biosurfactantes más eficaces son capaces de reducir

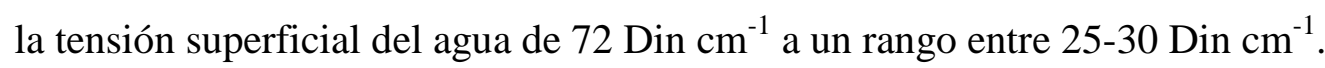

Finalmente, la presencia de biosurfactantes tiene un claro efecto en el consumo de HXD ya sea limitando la transferencia de oxígeno o que estos sean consumidos en lugar del HXD residual. En la etapa de estancamiento del consumo, todo el HXD residual estaría emulsificado (suponemos que nuestra técnica de separación líquido-líquido rompe la emulsión y por eso es posible detectar HXD en el cromatógrafo de gases) por lo que las bacterias no lo consumirían, esto explicaría la observación de que al restituirse la tensión superficial el HXD quede nuevamente libre y debido a esto se reanude el consumo. Para tratar de explicar, microscópicamente, lo que ocurre durante la cinética se tomaron imágenes a 100X de muestras a las que se les añadió rodofila para teñir al HXD y azul de metileno para teñir las bacterias. En la Figura 9.4.2 se muestran las imágenes para los diferentes tiempos de la cinética en donde se observan las gotas de HXD en color anaranjado y las bacterias en color azul. Al inicio de la cinética (ver Figura 9.4.2. a y b) claramente se distinguen las gotas de HXD y las células; posteriormente se muestran gotas de HXD (ver Figura 9.4.2 c y d) rodeadas de células que aparentemente están adheridas al hidrocarburo sugiriendo que hay un consumo por contacto directo; las micelas de HXD-biosurfactante, desafortunadamente, no se pueden apreciar en nuestras imágenes; sin embargo, en las muestras finales (ver Figura 9.4.2 e y f) tampoco el HXD se resuelve con claridad. Nuestros resultados sugieren que hay un consumo directo del HXD en las etapas iniciales del consumo, que prevalece al principio de la etapa de estancamiento de nuestro estudio. Si fuera cierto que las células se encuentran adheridas a las gotas de hidrocarburo esto concordaría con los resultados obtenidos por Dorobantu et al, 2004 en donde a través de microscopia de barrido de una emulsión estable aceite en agua (agua y 
HXD) observan claramente células bacterianas de Rhodococcus erythropolis adheridas en la superficie de gotas de HXD.

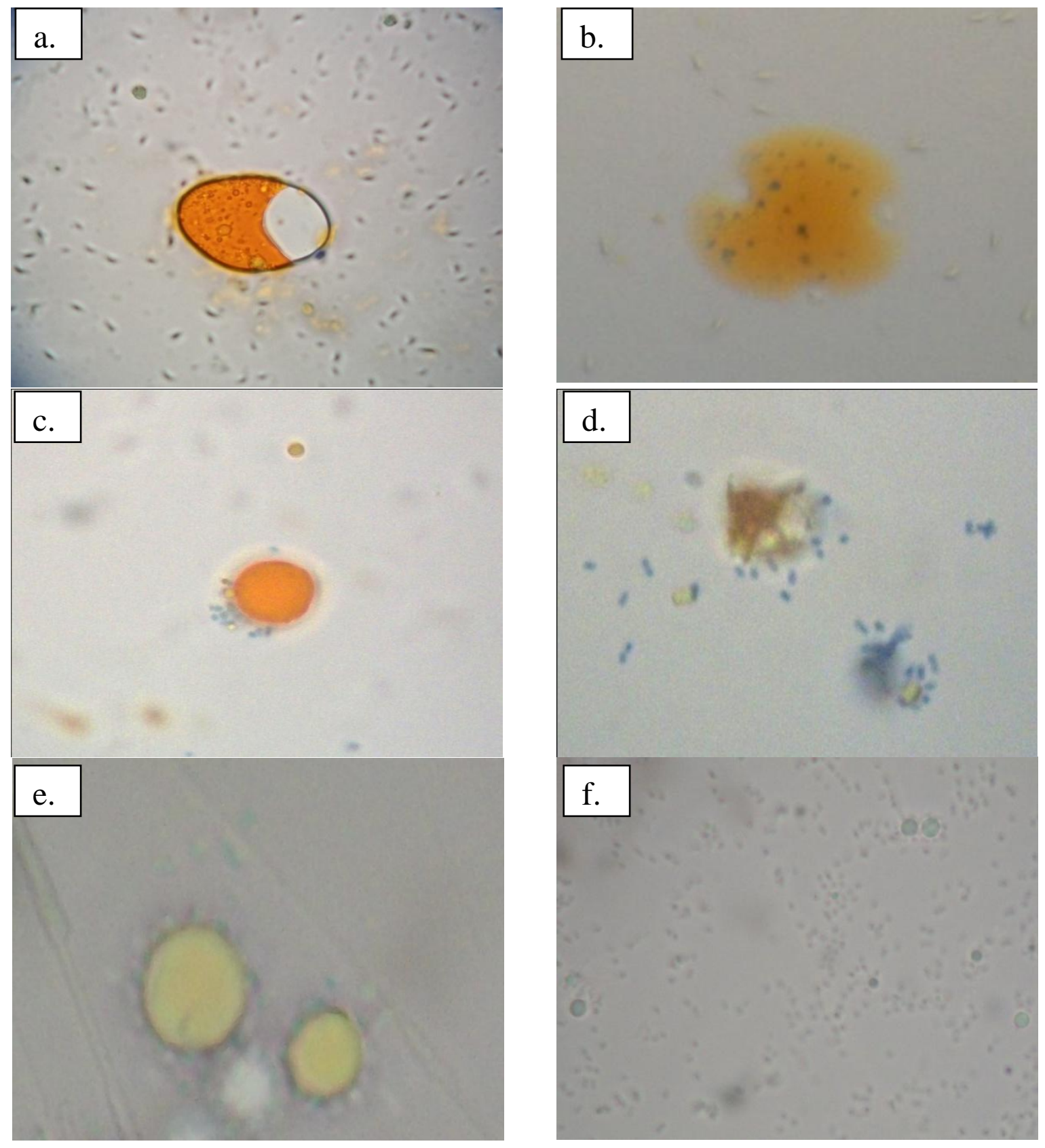

Figura 9.4.2. Imágenes microscópicas obtenidas para diferentes tiempos: a. Inicio de la cinética (t0). b. Después de 3.33 h de cultivo (t2). c. 5 h de cultivo (t3). d. 8.33 h de cultivo (t5). e. $26.66 \mathrm{~h}$ de cultivo (t9) f. $46 \mathrm{~h}$ de cultivo (t12). 
Durante toda la experimentación anterior sólo se puede deducir que los biosurfactantes intervienen en la presencia de esta etapa de estancamiento pero se desconoce si es porque son consumidos preferentemente o porque limitan la transferencia de masa ya sea el transporte de oxígeno, de la fase gas a la fase líquida o de la fase líquida a las células. Por lo que se decidió evaluar los coeficientes volumétricos de transferencia de oxígeno, de la fase gas a la fase líquida durante el cultivo

\subsection{Variación de $k_{L} a$}

Un factor importante que pudiera estar relacionado con la utilización del HXD como única fuente de carbono y energía es la transferencia de oxígeno, en donde la presencia de biosurfactantes podría ser un factor limitante. Para demostrar esto se midió el $\mathrm{k}_{\mathrm{L}}$ a a lo largo de una cinética con velocidad de aireación de $2.7 \mathrm{~cm} \mathrm{~s}^{-1}$, y el resultado se muestra en la Figura 9.5.1 que muestra la correspondencia de la variación de $\mathrm{k}_{\mathrm{L}}$ a con la degradación de $\mathrm{HXD}$ a lo largo de la cinética. Se observa que los valores más bajos para $\mathrm{k}_{\mathrm{L}}$ a se presentan durante la etapa de estancamiento sugiriendo que los biosurfactantes que provocan un ligero descenso en la tensión superficial de acuerdo con lo discutido antes (ver Figura 9.4.1) interfieren también con la transferencia de oxígeno, ya que el $\mathrm{k}_{\mathrm{L}} \mathrm{a}$ se restablece significativamente al finalizar el estancamiento coincidiendo con el momento en el que la tensión superficial se restablece (ver Figura 9.4.1). Asgharpour et al en el 2010 observan, para un experimento realizado con agua y surfactante, que la presencia del surfactante provoca un aumento en el diámetro de las burbujas y que este efecto se incrementa a Ug altas, en concordancia con los resultados de nuestro trabajo, sugiriendo que los surfactantes limitan la transferencia de oxígeno debido a la coalescencia de las burbujas. Además, si se considera que a Ug altas se favorece la

coalescencia, esto explicaría por qué con la Ug de $2.7 \mathrm{~cm} \mathrm{~s}^{-1}$ el tiempo de tratamiento se incrementa comparado con la Ug de $0.6 \mathrm{~cm} \mathrm{~s}^{-1}$. 


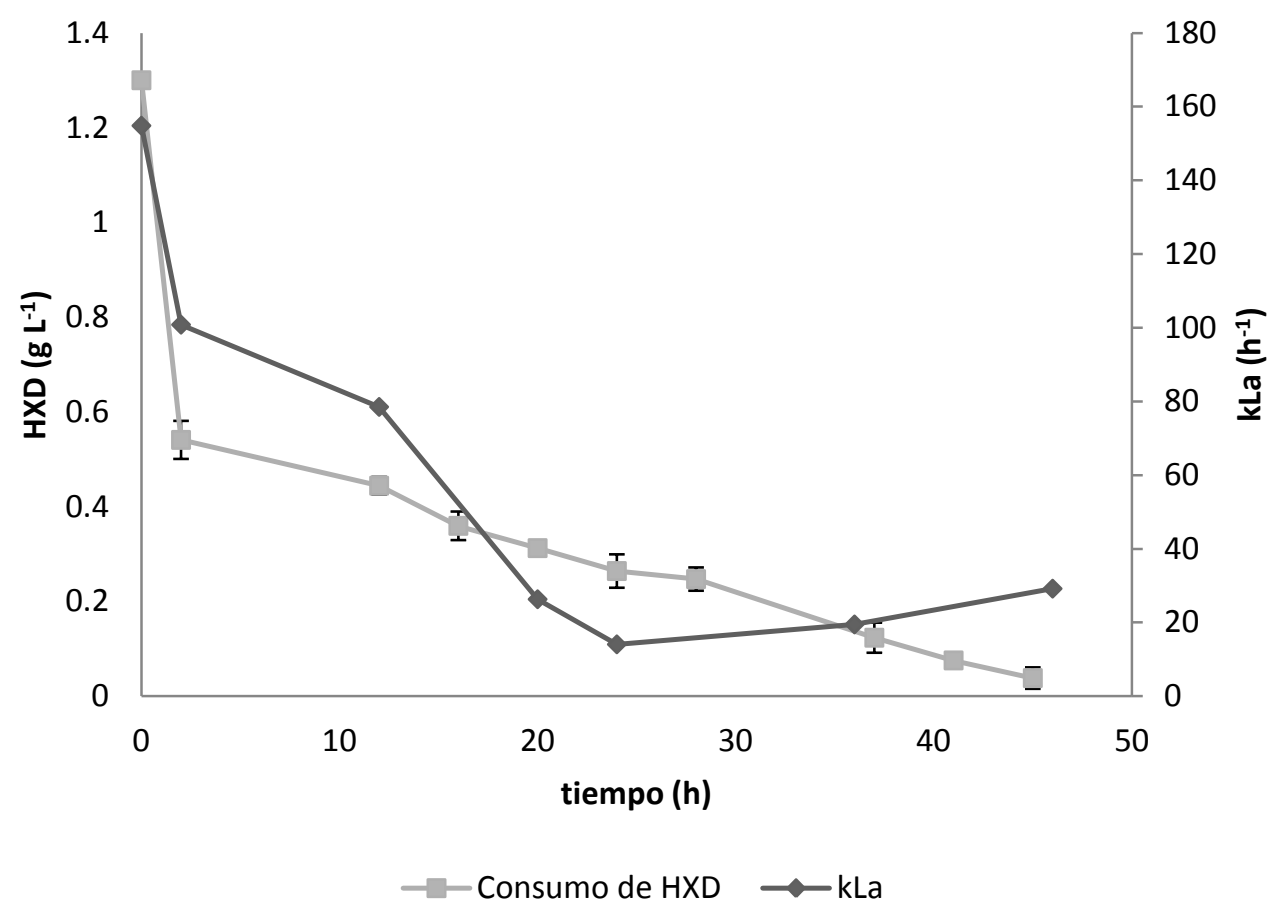

Figura 9.5.1 Variación del $\mathrm{k}_{\mathrm{L}}$ a y consumo de HXD con $\mathrm{Ug}$ de $2.7 \mathrm{~cm} \mathrm{~s}^{-1}$.

Los valores obtenidos de $\mathrm{k}_{\mathrm{L}}$ a son similares a los publicados por Lizardi-Jiménez et al en el 2012 medidos en un BAL de 10 L utilizando el mismo medio mineral con una concentración diez veces mayor y $1.3 \mathrm{~g} \mathrm{~L}^{-1}$ de HXD. Estos autores obtienen para un rango de Ug de $0.15 \mathrm{a}$ $2.7 \mathrm{~cm} \mathrm{~s}^{-1}$ valores de $\mathrm{k}_{\mathrm{L}}$ a en un rango de 26.17 a $45.65 \mathrm{~h}^{-1}$ análogo con lo obtenido en este trabajo para un rango de $\mathrm{Ug}$ de 0.37 a $3.20 \mathrm{~cm} \mathrm{~s}^{-1}$ con los que se obtuvieron valores de $\mathrm{k}_{\mathrm{L}}$ a de 3.5 a $53.5 \mathrm{~h}^{-1}$ 


\section{Conclusiones}

1. No se puede asegurar una relación directa entre el consumo de HXD y el aumento de Ug durante las primeras horas debido a la dificultad de obtener datos al inicio de las cinéticas. El consumo de HXD fue proporcional al aumento de Ug durante las primeras 10-12 horas; para las siguientes 34 horas, el consumo de HXD fue independiente de la Ug. El rendimiento final de SS (base sustrato consumido) fue independiente de la Ug.

2. Reinocular no modificó el patrón de consumo de HXD. La producción final de SS fue independiente de la concentración celular en el medio.

3. Durante la etapa de estancamiento la tensión superficial disminuyó, probablemente debido a la presencia de biosurfactantes que podrían limitar el consumo de HXD y disminuir $\mathrm{k}_{\mathrm{L}} \mathrm{a}$.

4. Los resultados sugieren que el mecanismo principal de consumo de HXD fue por contacto directo de las células con el hidrocarburo. 


\section{Recomendaciones}

1. Para evitar la zona de estancamiento y llegar a la concentración de $40 \mathrm{mg} \mathrm{L}^{-1}$ sería necesario utilizar otro tratamiento justo antes de llegar a la zona de estancamiento tal como un humedal que es un biorreactor de bajo costo.

2. Analizar si el HXD es mineralizado y los intermediarios que se forman son tóxicos.

3. Para eliminar o disminuir la zona de estancamiento se puede probar la desestabilización de las emulsiones.

4. Es necesario determinar con más claridad los factores fisiológicos, bioquímicos que influyen en la presencia de la zona de estancamiento con la finalidad de entender el proceso más a fondo y de esta manera determinar si esta zona puede ser prescindida y como.

5. Identificar los intermediarios producidos durante la biodegradación de HXD y experimentalmente determinar si dichos compuestos inhiben la degradación del hidrocarburo o son consumidos preferentemente. 


\section{Bibliografía}

1. Abbasnezhad H., Gray M., Foght JM. 2011. Influence of adhesion on aerobic biodegradation and bioremediation of liquid hydrocarbons. Applied Microbiology and Biotechnology, 92: 653-675.

2. Asgharpour M., Mehrnia M.R., Mostoufi M. 2010. Effect of surface contaminants on oxygen transfer in bubble column reactors. Biochemical Engineering Journal, 49: 351360.

3. Atlas Ronald M., Bartha R. Ecología microbiana y microbiología ambiental., $4^{\mathrm{a}}$ Ed. PEARSON, España 2006.

4. Awashti N.; Kumar A.; Makkar R.; Cameotra S. 1999. Enhanced biodegradation of endosulfan, a chlorinated pesticide in presence of a biosurfactant. Journal of Environmental Science and Health B, 34: 793-803.

5. Bouchez-Naïtali M., Vandecasteele J.P. 2008. Biosurfactants, an help in the biodegradation of hexadecane? The case of Rhodococcus and Pseudomonas strains. Journal of Microbiology and Biotechnology, 24:1901-1907

6. Camacho R. F., Garcia J.L., Molina E., Chisti Y. 2001. Axial inhomogeneites in steady-state disolved oxygen in airlift bioreactors: predictive models. Chemical Engineering Journal, 84: 43-55.

7. Cameron D.R.; Cooper D.G.; Neufeld R.J. 1988. The mannoprotein of Saccharomyces cerevisiae is an effective bioemulsifier. Applied Environmental. Microbiology, $54: 1420-1425$. 
8. Cirigliano M.C.; Carman G.M. 1984. Purification and characterization of liposan, a bioemulsifier from Candida lipolytica. Applied Environmental Microbiology, 50:846850.

9. Chan. Y.J., Chong. M.F., Law. C.L., Hassell. D.G. 2009. A review on anaerobic aerobic treatment of industrial and municipal wastewater. Chemical Engineering Journal, 155: 1-18

10. Chisti M.Y. 1989. Airlift Bioreactors, editorial Elsevier London.

11. Clarke K.G., Correia L.D.C. 2008. Oxygen transfer in hydrocarbon-aqueous dispersions and its applicability to alkane bioprocesses: A review. Biochemical Engineering Journal, 39: 405-429.

12. Díaz-Ramírez I.J., Ramírez-Saad H., Gutiérrez-Rojas M., Favela-Torres E. 2004. Biodegradation of Maya crude oil fractions by bacterial strains and a defined mixed cultura isolated from Cyperus laxus rhizosphere soil in a contaminated site. Canadian Journal of Microbiology, 49: 755-761.

13. Díaz Ramírez I.J. Tesis de Maestría. Universidad Autónoma Metropolitana-Iztapalapa, México, D.F. 2000.

14. Dorobantu L.S., Yeung A. K. C., Foght J. M., Gray R. M. 2004. Stabilization of OilWater Emulsions by Hydrophobic Bacteria. Applied and Environmental Microbiology, 70: 6333-6336

15. Droste R.L. Theory and Practice of Water and Wastewater Treatment, editorial John Wiley \& Sons, Inc., 1997. 
16. Ferrer Polo J., Seco Torrecillas A., Tratamientos biológicos de aguas residuales, editorial UPV., Valencia 2003.

17. Fujio Y., Sambuichi M., Ueda S. 1973. Numerical method of the determination of kLa and respiration rate in biological system. Journal of Fermentation Technology, 51: 154-158.

18. Franzetti A., Gandolfi, I., Bestetti G., Smyth T.J., Banat I.M. 2010. Production and applications of trehalose lipid biosurfactants. European Journal of Lipidic Science and. Technology, 112: 617-627.

19. Gargouri B., Karray F., Mhiri N., Alouia F., Sayadi S. 2011. Application of a continuously stirred tank bioreactor (CSTR) for bioremediation of hydrocarbon-rich industrial wastewater effluents. Journal of Hazardous Materials, IN PRESS.

20. Ghazali F.M., Zaliha R.N.R., Salleh A.B., Basri M. 2004. Biodegradation of hydrocarbons in soil by microbial consortium. International Biodeterioration and Biodegradation, 54: 61-67.

21. Gray N.F. Biology of Wastewaters Treatment, $2^{\mathrm{a}}$ ed., editorial ICP, London 2004.

22. Jajuee B., Margaritis A., Karamanev D., Bergougnou M. A. 2006. Influence of dissolved hydrocarbons on volumetric oxygen mass transfer coefficient in a novel airlift contactor. Chemical Engineering Science, 61: 4111-4119.

23. Jin. B., Yu. Q., Yan. X.Q., van Leeuwen J. 2001. Characterization and improvement of oxygen transfer in pilot plant external air-lift bioreactor for mycelial biomass production. World Journal of Microbiology and Biotechnology, 17: 265-272. 
24. Khopade A., Ren B., Liu X-Y., Mahadik K., Zhang L., Kokare C. 2012. Production and characterization of biosurfactant from marine Streptomyces species B3. Journal of Colloid and Interface Science, 367:311-318.

25. Liang Z., Zhennmin M., Qingguo L. 2009. Study on Pollution Mechanism of Petroleum Contamination in a Groundwater System under a Refinery in Jinan City. International Conference on Environmental Science and Information Application Technology, 106-108

26. Lin C., Gan L., Chen Z L. 2010. Biodegradation of naphthalene by strain Bacillus fusiformis (BFN). Journal of Hazardous Materials, 182: 771-777.

27. Lizardi-Jiménez M. A., Saucedo-Castañeda G., Thalasso F., Gutiérrez-Rojas M. 2012. Simultaneous hexadecane and oxygen transfer rate on the production of an oildegrading consortium in a three-phase airlift bioreactor. Chemical Engineering Journal. (EN PRENSA DOI: 10.1016/j.cej.2012.01.114)

28. Lizardi-Jiménez M. A. 2011. Contribución al estudio de la hidrodinámica y transferencia simultánea de masa en biorreactores airlift de tres fases: producción de un consorcio microbiano degradador de petróleo, Universidad Autónoma MetropolitanaIztapalapa.

29. Martínez-Checa F., Toledo F.L., El Mabrouki K., Quesada E., Calvo C. 2007. Characteristics of bioemulsifier V2-7 synthesized in culture media added of hydrocarbons: Chemical composition, emulsifying activity and rheological properties. Bioresource Technology, 98: 3130-3135.

30. Medina Moreno S.A. Estudio y modelamiento matemático de la biodegradación de hidrocarburos en biorreactores heterógeneos, 2006, Tesis de doctorado, Universidad Autónoma Metropolitana-Iztapalapa. 
31. Medina-Moreno S.A., Huerta-Ochoa S., Gutiérrez-Rojas M. 2005. Hydrocarbon biodegradation in oxygen-limited sequential batch reactors by consortium from weathered, oil-contaminated soil. Canadian Journal of Microbiology, 51: 231-239.

32. Navarro. A. R., Lopez. Z. O., Maldonado. M. C. 2008. A pilot plant for the treatment of lemon industry wastewater. Clean Technology Environmental Policy, 10:371-375

33. Norma Oficial Mexicana NOM-143-SEMARNAT-2003.

34. Ochieng A., Ogada T., Sisenda W., Wambua P. 2002. Brewery wastewater treatment in a fluidised bed bioreactor. Journal of Hazardous Materials B, 90: 311-321

35. Ochieng, A. Odiyo J.O., Mutsago M. 2003. Biological treatment of mixed industrial wastewaters in a fluidized bed reactor. Journal of Hazardous Materials B, 96: 79-90

36. Pacwa-Plociniczac M., Plaza GA., Piotrowska-Seget Z., Cameotra SS. 2011. Environmental Applications of Biosurfactants: Recent Advances. International Journal of Molecular Sciences, 12: 633-654.

37. Painmanakul P., Loubière K., Hébrard G., Mietton-Peuchot M., Roustan M. 2005. Effect of surfactants on liquid-side mass transfer coefficients. Chemical. Engineering Science, 60: 6480-6491.

38. PEMEX, Informe de responsabilidad social 2009

39. Pepi M., Cesàro A., Liut G., Baldi F. 2005. An antartic psychrotrophic bacterium Halomonas sp. ANT-3b, growing on n-hexadecane, produces a new emulsifying glycolipid. FEMS. Microbiology Ecology, 53: 157-166. 
40. Plaza A.G., Jangid K., Lukasik K., Nalecz-Jawecki G., Berry C.J., Brigmon R.L. 2008. Reduction of petroleum hydrocarbons and toxicity in refinery wastewater by bioremediation. Bulletin of Environmental Contamination and Toxicology, 81:329333.

41. Quijano-Govantes G. 2006. Evaluación de los coeficientes de transferencia masa y cinéticos en un biorreactor de tres fases para la degradación de hexadecano, Tesis de Maestría Universidad Autónoma Metropolitana-Iztapalapa.

42. Riojas-González H. H., Torres-Bustillos L. G., Mondaca-Fernández I., Balderas-Cortes J. J., Gortáres-Moroyoqui P. 2010. Efectos de los surfactantes en la biorremediación de suelos contaminados con hidrocarburos. Química Viva, 9 (3).

43. Röling W. F. M., Milner M. G., Jones D. M., Lee K., Daniel F., Swannell R. J. P., Head I. M. 2002. Robust hydrocarbon degradation and dynamics of bacterial communities during nutrient-enhanced oil spill bioremediation. Applied and Environmental Microbiology, 68: 5537-5548.

44. Saval S. 2000. Bioremediation: clean-up biotechnologies for soils and aquifers. ENVIRONMENTAL BIOTECHNOLOGY AND CLEANER BIOPROCESSES. Editores: Olguin E.J., Sanchez G., y Hernandez E. Taylor \& Francis. USA.

45. Saravanan P., Pakshirajan K., Saha P. 2009. Treatment of phenolics containing synthetic waste water in an internal loop airlift bioreactor (ILALR) using indigenous mixed strainof Pseudomonas sp. under continuous mode of operation. Bioresource Technology, 100: 4111-4116.

46. Toren A., Navon-Venezia S., Ron E.Z., Rosenberg E. 2001. Emulsifying activity of purified alasan proteins from Acinetobacter radioresistens. Applied Environmental Microbiology, 67: 1102-1106. 
47. Thomas C.P., Duvall M.L., Robertson E.P., Barrett K.B., Bala G.A. 1993. Surfactantbased EOR mediated by naturally occurring microorganisms. SPE Reservoir Engineering, 11: 285-291.

48. Tzintzun-Camacho O., Loera O., Ramírez-Saad H., Gutiérrez-Rojas M. 2012. Comparison of mechanisms of hexadecane uptake among pure and mixed cultures derived from a bacterial consortium. International Biodeterioration and Biodegradation. (EN PRENSA DOI: 10.1016/j.ibiod.2012.01.009).

49. Van-Hamme J.D., Singh A., Ward O.P. 2003. Recent Advances in Petroleum Microbiology. Microbiology and Molecular Biology Reviews, 67: 503-549.

50. Vinod A.V., Reddy G.V. 2006. Mass transfer for phenol biodegradation in a fluidized bed bioreactor. Journal of Hazardous Materials, 136: 727-734

51. Whang L.M., Liu P.W.G., Ma C.C., Cheng S.S. 2008. Application of biosurfactant, rhamnolipid, and surfactin, for enhanced biodegradation of diesel-contaminated water and soil. Journal of Hazardous. Materials, 151: 155-163.

52. Xianling L., Jianping W., Qing Y., Xueming Z. 2005. The pilot study for oil refinery wastewater treatment using a gas-liquid-solid three-phase flow airlift loop bioreactor. Biochemical Engineering Journal, 27: 40-44.

53. Zanaroli G., Di Toro S., Todaro D., Varese GC., Bertolotto A., Fava F. 2010. Characterization of two diesel fuel degrading microbial consortia enriched from a nonacclimated, complex source of microorganisms. Microbial Cell Factories, 9:10 
54. Zhao Z., Selvam A., Wong J.W. 2011. Effects of rhamnolipids on cell surface hydrophobicity of PAH degrading bacteria and the biodegradation of phenanthrene. Bioresource Technology, 102: 3999-4007.

55. Zosim Z., Gutnick D.L., Rosenberg E. 1982. Properties of hydrocarbon-in-water emulsions stabilized by Acinetobacter RAG-1 emulsan. Biotechnology. Bioengineering, 24: 281-292. 